\title{
Máscaras de tecido em locais públicos: intervenção essencial na prevenção da COVID-19 no Brasil
}

\author{
Cloth masks in public places: \\ an essential intervention to prevent COVID-19 in Brazil
}

Naiá Ortelan (https://orcid.org/0000-0001-6535-748X) ${ }^{1}$

Andrêa Jacqueline Fortes Ferreira (https://orcid.org/0000-0002-6884-3624) ${ }^{2}$

Luciana Leite (https://orcid.org/0000-0003-1745-4271) ${ }^{3}$

Julia Moreira Pescarini (https://orcid.org/0000-0001-8711-9589) ${ }^{1}$

Ana Cristina Souto (https://orcid.org/0000-0002-8436-9264) ${ }^{2}$

Mauricio Lima Barreto (https://orcid.org/0000-0002-0215-4930) ${ }^{1}$

Estela M. L. Aquino (http://orcid.org/0000-0002-8204-1249) ${ }^{2}$
${ }^{1}$ Centro de Integração de Dados e Conhecimentos para Saúde, Fiocruz Bahia. R. Mundo $s / n$, Trobogy. 41745-715 Salvador BA Brasil. nana.ortelan@gmail.com ${ }^{2}$ Instituto de Saúde Coletiva, Universidade Federal da Bahia (UFBA). Salvador BA Brasil.

${ }^{3}$ Instituto de Biologia, UFBA. Salvador BA Brasil.

\begin{abstract}
There is increasing evidence that the use of masks is an indispensable protective measure against COVID-19, given the high transmissibility of the new coronavirus through the respiratory system, including by asymptomatic individuals. The use of cloth masks in public places has been established as a protective measure to be adopted alongside social distancing and hand hygiene. This narrative review aims to systemati$z e$ the scientific evidence that informs the widespread use of cloth masks as a preventive measure against COVID-19 and to describe the evolution of positions contrary to or in favor of its use outside the home, in view of the advance of the new coronavirus pandemic globally. The scientific articles, technical notes, governmental decrees and other documents analyzed indicate that widespread use of masks has the potential to reduce the spread of the new coronavirus. We recommend that the Brazilian government adopt strategies to increase the supply of reusable cloth masks to the public, especially to vulnerable populations and to support studies on the impact of this measure to control the pandemic in the country. Finally, it is imperative to ensure that use of masks does not exacerbate stigmatization of racial groups that already face prejudice.
\end{abstract}

Key words Cloth masks, Homemade masks, COVID-19, SARS-CoV-2, Novel coronavirus
Resumo Acumulam-se evidências de que o uso de máscaras é uma medida indispensável de proteção à COVID-19, devido ao alto poder de transmissão do novo coronavírus por via respiratória, inclusive por indivíduos assintomáticos. Por sua vez, o uso das máscaras de tecido em locais públicos tem se consolidado como medida adicional de proteção às medidas de distanciamento social e higienização das mãos. Objetivou-se sistematizar as evidências científicas que justificam o amplo uso de máscaras de tecido como prevenção à COVID-19 e descrever a evolução dos posicionamentos contrários ou favoráveis ao seu uso em ambientes extradomiciliares, diante do avanço da pandemia do novo coronavirus pelo mundo. A triagem de artigos e documentos oficiais do Brasil e de outros países indica que o uso de máscaras em locais públicos tornou-se uma intervenção essencial graças ao potencial de reduzir a velocidade de propagação do novo coronavírus. Recomenda-se que o poder público adote estratégias para aumentar a oferta deste produto e fomente estudos para avaliação do impacto da medida no controle da pandemia no Brasil. É imperativo assegurar disponibilidade de máscaras a grupos socioeconomicamente desfavorecidos e garantir que determinados grupos raciais não sejam estigmatizados diante do uso de máscaras em ambientes extradomiciliares.

Palavras-chave Máscaras de tecido, Máscaras caseiras, COVID-19, SARS-CoV-2, Novo coronavírus 


\section{Introdução}

Desde a emergência do vírus da síndrome respiratória aguda grave 2 (SARS-CoV-2), debates sobre medidas de controle da pandemia têm ganhado destaque na mídia e na literatura científica. Sabese que a transmissão do novo coronavírus entre humanos ocorre principalmente na interação pessoa-pessoa pelo contato com gotículas produzidas por via oral e nasal (na respiração, fala, tosse ou espirro de indivíduos infectados, sejam doentes ou assintomáticos) e que o vírus permanece em boas condições no ar por até três horas e em superfícies rígidas por até 72 horas $^{1-3}$.

Devido a sua prolongada viabilidade em alguns materiais no ambiente, o SARS-CoV-2 pode também ser transmitido mediante o contato com superfícies contaminadas ${ }^{2,4}$. Desse modo, as primeiras recomendações para evitar a disseminação da doença foram o amplo distanciamento social e a higienização correta e frequente das mãos ${ }^{5-8}$; e, para pacientes sintomáticos ou que testaram positivo para o SARS-CoV-2, o isolamento domiciliar e a quarentena dos seus respectivos contatos?.

Com o avançar da pandemia, o uso ampliado das máscaras em ambientes extradomiciliares (estabelecimentos comerciais, parques, locais de trabalho, transportes públicos, entre outros) passou a ser discutido como medida adicional de proteção, a partir da experiência acumulada por outros países em epidemias prévias ${ }^{10}$. O debate sobre essa proposição se fortaleceu devido ao papel de indivíduos assintomáticos, oligossintomáticos ou pré-sintomáticos na disseminação da doença $a^{11-13}$, diante das evidências de que a COVID-19 apresenta um longo período de incubação ${ }^{14-16}$ e do entendimento de que há uma alta carga viral no estágio inicial da doença ${ }^{12,17-19}$.

A adoção de uma política universal de uso de máscaras descartáveis durante a pandemia, resultaria em uma demanda difícil de ser atendida ocasionando a escassez do equipamento de proteção para profissionais de saúde e demais usuários recorrentes ${ }^{20,21}$. No início de abril, a Organização Mundial da Saúde (OMS) recomendava que as máscaras descartáveis fossem utilizadas exclusivamente por profissionais de saúde, indivíduos imunossuprimidos e casos suspeitos ou confirmados do novo coronavírus. A OMS alertava ainda sobre a ausência de evidências que embasassem a indicação do amplo uso de máscaras feitas a partir de materiais alternativos'. Somente no dia 5 de junho de 2020, a OMS divulgou orientações para uso e fabricação de máscaras de pano como proteção contra a COVID-19, e passou a recomendar o amplo uso em locais onde há ampla transmissão da doença e em situações em que o distanciamento social não é possível, como no transporte público ${ }^{22}$.

Esse artigo tem o objetivo de realizar uma revisão narrativa da literatura sobre a eficácia e adesão ao uso de máscaras de tecido em locais públicos para a prevenção da COVID-19 e descrever a evolução dos posicionamentos contrários ou favoráveis ao seu uso em ambientes extradomiciliares, diante do avanço da pandemia do novo coronavírus pelo mundo.

\section{Métodos}

Esta revisão narrativa partiu do levantamento de artigos sobre o uso de máscaras no contexto do novo coronavírus, publicados na base Medline (PubMed), que só inclui publicações aprovadas por peer review ${ }^{23}$, contempla a base SciElO e também manuscritos em fase de pré-publicação (preprints) disponíveis nas bases do MedRxiv, constituindo, assim, o maior e principal repositório da literatura biomédica disponível.

Para a seleção de artigos relevantes, buscamos as palavras-chave "mask and covid" or "mask and coronavirus", or "mask and covid-19", or "mask and covid19" nos títulos e resumos de artigos publicados até o dia 12 de junho de 2020. Foram incluídos artigos originais, editoriais, cartas ao editor, comentários e revisões de literatura, em português, inglês e espanhol disponíveis na íntegra. Foram excluídos artigos que apresentassem dados exclusivos referentes ao uso de máscaras cirúrgicas (TNT e variantes), máscaras respiratórias (N95, FFP2) e descartáveis; que tratassem de máscaras faciais destinadas à cobertura de outras porções da face, não incluindo o trato respiratório (e.g. máscaras para os olhos e face shields) e referentes ao uso de máscaras apenas entre profissionais de saúde.

Além dos artigos científicos selecionados, foram consultados documentos oficiais estaduais e federais implementados no Brasil, tais como decretos, portarias e leis estaduais disponíveis no site LegisWeb ${ }^{24}$; notas técnicas do Ministério da Saúde do Brasil (MS) e da Agência Nacional de Vigilância Sanitária (ANVISA); e regulamentações sobre o uso de máscaras de tecido em ambientes extradomiciliares adotadas em outros países no contexto da pandemia da COVID-19. Para tal, as informações foram extraídas do site Mask4Al25, uma organização não-governamental 
que reúne informações relativas à regulamentação do uso de máscaras em todos os países. Todas as fontes de informações descritas foram consultadas até o dia 12 de junho.

Uma síntese quantitativa dos principais achados dos artigos selecionados foi realizada, com extração das seguintes informações: autoria, revista, título, data de publicação, tipo de publicação e posicionamento relacionado à recomendação do uso de máscaras de tecido como medida de prevenção e controle da COVID-19 (Quadro 1). Os posicionamentos dos autores sobre o uso de máscaras de tecido no contexto da COVID-19 foram classificados como: i) A favor; ii) Sem posiciona- mento; e iii) Contra. A evolução temporal desses posicionamentos foi analisada de forma gráfica.

Adicionalmente, extraíram-se informações referentes à adesão e eficácia do uso de máscaras de tecido descritas nos artigos selecionados. Uma síntese qualitativa dos principais achados sobre o uso de máscaras de tecido em ambientes extradomiciliares, os argumentos que embasaram os posicionamentos a favor e contra o seu uso, bem como possíveis diferenças observadas entre os países quanto à adoção dessa recomendação, também foi realizada. Dessa forma, as informações obtidas foram sintetizadas e discutidas com base nas evidências publicadas até o momento.

Quadro 1. Artigos selecionados quanto ao seu posicionamento com relação ao amplo uso de máscaras de tecido.

\begin{tabular}{|c|c|c|c|c|c|}
\hline Autor(es) & Revista & Título & $\begin{array}{l}\text { Data de } \\
\text { publicação } \\
\text { (dd/mm/ } \\
\text { aa) }\end{array}$ & $\begin{array}{c}\text { Tipo de } \\
\text { publicação }\end{array}$ & $\begin{array}{c}\text { Posição relacionada } \\
\text { à adoção do uso de } \\
\text { máscara facial }\end{array}$ \\
\hline Leung et al. ${ }^{26}$ & $\begin{array}{l}\text { The International } \\
\text { Journal of } \\
\text { Tuberculosis and } \\
\text { Lung Desease }\end{array}$ & $\begin{array}{l}\text { Let us not forget the mask in our } \\
\text { attempts to stall the spread of COVID-19 }\end{array}$ & $\begin{array}{l}4-\text { jan- } \\
2020\end{array}$ & Editorial & $\begin{array}{l}\text { A favor do uso de } \\
\text { máscaras em locais } \\
\text { públicos }\end{array}$ \\
\hline $\begin{array}{l}\text { Zhong et } \\
\text { al. }^{27}\end{array}$ & $\begin{array}{l}\text { International } \\
\text { Journal of } \\
\text { Biological Sciences }\end{array}$ & $\begin{array}{l}\text { Knowledge, attitudes, and practices } \\
\text { towards COVID-19 among Chinese } \\
\text { residents during the rapid rise period of } \\
\text { the COVID-19 outbreak: a quick online } \\
\text { cross-sectional survey }\end{array}$ & $\begin{array}{l}15-\text { mar- } \\
2020\end{array}$ & $\begin{array}{l}\text { Estudo } \\
\text { transversal }\end{array}$ & $\begin{array}{l}\text { A favor do uso de } \\
\text { máscaras em locais } \\
\text { públicos }\end{array}$ \\
\hline $\begin{array}{l}\text { Adhikari et } \\
\text { al. }{ }^{28}\end{array}$ & $\begin{array}{l}\text { Infectious Diseases } \\
\text { of Poverty }\end{array}$ & $\begin{array}{l}\text { Epidemiology, causes, clinical manifestation } \\
\text { and diagnosis, prevention and control of } \\
\text { coronavirus disease (COVID-19) during } \\
\text { the early outbreak period: a scoping review. }\end{array}$ & $\begin{array}{l}17-\text { mar- } \\
2020\end{array}$ & $\begin{array}{l}\text { Scoping } \\
\text { review }\end{array}$ & $\begin{array}{l}\text { A favor do uso de } \\
\text { máscaras em locais } \\
\text { públicos }\end{array}$ \\
\hline Leung et al. ${ }^{29}$ & The Lancet & $\begin{array}{l}\text { Mass masking in the COVID-19 } \\
\text { epidemic: people need guidance }\end{array}$ & $\begin{array}{l}21-\text { mar- } \\
2020\end{array}$ & Comentário & $\begin{array}{l}\text { A favor do uso de } \\
\text { máscaras em locais } \\
\text { públicos }\end{array}$ \\
\hline Zhai $^{30}$ & $\begin{array}{l}\text { Building and } \\
\text { Environment }\end{array}$ & $\begin{array}{l}\text { Facial mask: A necessity to beat } \\
\text { COVID-19 }\end{array}$ & $\begin{array}{l}23-\text { mar- } \\
2020\end{array}$ & Comentário & $\begin{array}{l}\text { A favor do uso de } \\
\text { máscaras em locais } \\
\text { públicos }\end{array}$ \\
\hline $\begin{array}{l}\text { Liu e } \\
\text { Zhang }^{31}\end{array}$ & $\begin{array}{l}\text { Influenza and } \\
\text { Other Respiratory } \\
\text { Viruses } \\
\end{array}$ & $\begin{array}{l}\text { Face masks and human-to-human } \\
\text { transmission }\end{array}$ & $\begin{array}{l}29-\text { mar- } \\
2020\end{array}$ & $\begin{array}{l}\text { Carta ao } \\
\text { editor }\end{array}$ & $\begin{array}{l}\text { A favor do uso de } \\
\text { máscaras em locais } \\
\text { públicos }\end{array}$ \\
\hline Ma et al. ${ }^{32}$ & $\begin{array}{l}\text { Journal of Medical } \\
\text { Virology }\end{array}$ & $\begin{array}{l}\text { Potential utilities of mask-wearing and } \\
\text { instant hand hygiene for fighting SARS- } \\
\text { CoV-2 }\end{array}$ & $\begin{array}{l}31-\text { mar- } \\
2020\end{array}$ & $\begin{array}{l}\text { Estudo } \\
\text { transversal }\end{array}$ & $\begin{array}{l}\text { A favor do uso de } \\
\text { máscaras em locais } \\
\text { públicos }\end{array}$ \\
\hline $\begin{array}{l}\text { Worby e } \\
\text { Chang }^{33}\end{array}$ & medRxiv preprint & $\begin{array}{l}\text { Face mask use in the general population } \\
\text { and optimal resource allocation during } \\
\text { the COVID-19 pandemic }\end{array}$ & $\begin{array}{l}7-a b r- \\
2020\end{array}$ & $\begin{array}{l}\text { Estudo } \\
\text { transversal }\end{array}$ & $\begin{array}{l}\text { A favor do uso de } \\
\text { máscaras em locais } \\
\text { públicos }\end{array}$ \\
\hline Zhou et al. ${ }^{34}$ & $\begin{array}{l}\text { Journal of Medical } \\
\text { Virology }\end{array}$ & $\begin{array}{l}\text { Mask is the possible key for self-isolation } \\
\text { in COVID-19 pandemic }\end{array}$ & $\begin{array}{l}8 \text {-abr- } \\
2020\end{array}$ & $\begin{array}{l}\text { Carta ao } \\
\text { editor }\end{array}$ & $\begin{array}{l}\text { A favor do uso de } \\
\text { máscaras em locais } \\
\text { públicos }\end{array}$ \\
\hline
\end{tabular}


Quadro 1. Artigos selecionados quanto ao seu posicionamento com relação ao amplo uso de máscaras de tecido.

\begin{tabular}{|c|c|c|c|c|c|}
\hline Autor(es) & Revista & Título & $\begin{array}{c}\text { Data de } \\
\text { publicação } \\
\text { (dd/mm/ } / \text { aa) } \\
\text { aa) }\end{array}$ & $\begin{array}{c}\text { Tipo de } \\
\text { publicação }\end{array}$ & $\begin{array}{l}\text { Posição relacionada } \\
\text { à adoção do uso de } \\
\text { máscara facial }\end{array}$ \\
\hline Javid et al. ${ }^{35}$ & The BMJ & $\begin{array}{l}\text { Covid-19: should the public wear face } \\
\text { masks? }\end{array}$ & $\begin{array}{l}\text { 9-abr- } \\
2020\end{array}$ & Editorial & $\begin{array}{l}\text { A favor do uso de } \\
\text { máscaras em locais } \\
\text { públicos }\end{array}$ \\
\hline $\begin{array}{l}\text { Greenhalgh } \\
\text { et al. } .^{36}\end{array}$ & The BMJ & $\begin{array}{l}\text { Face masks for the public during the } \\
\text { covid-19 crisis }\end{array}$ & $\begin{array}{l}10-\text { abr- } \\
2020\end{array}$ & Comentário & $\begin{array}{l}\text { A favor do uso de } \\
\text { máscaras em locais } \\
\text { públicos }\end{array}$ \\
\hline Wang et al. ${ }^{37}$ & $\begin{array}{l}\text { Infection Control } \\
\text { \& Hospital } \\
\text { Epidemiology }\end{array}$ & $\begin{array}{l}\text { The COVID-19 outbreak: The issue of } \\
\text { face masks }\end{array}$ & $\begin{array}{l}13 \text {-abr- } \\
2020\end{array}$ & $\begin{array}{l}\text { Carta ao } \\
\text { editor }\end{array}$ & $\begin{array}{l}\text { A favor do uso de } \\
\text { máscaras em locais } \\
\text { públicos }\end{array}$ \\
\hline $\begin{array}{l}\text { Han e } \\
\text { Zhou }^{38}\end{array}$ & $\begin{array}{l}\text { Journal of Medical } \\
\text { Virology }\end{array}$ & $\begin{array}{l}\text { Possibly critical role of wearing masks } \\
\text { in general population in controlling } \\
\text { COVID-19 }\end{array}$ & $\begin{array}{l}15 \text {-abr- } \\
2020\end{array}$ & Comentário & $\begin{array}{l}\text { A favor do uso de } \\
\text { máscaras em locais } \\
\text { públicos }\end{array}$ \\
\hline $\begin{array}{l}\text { Gandhi e } \\
\text { Havlir }{ }^{39}\end{array}$ & $\begin{array}{l}\text { Open Forum } \\
\text { Infectious Diseases }\end{array}$ & $\begin{array}{l}\text { The time for universal masking of the } \\
\text { public for coronavirus disease } 2020 \text { is } \\
\text { now }\end{array}$ & $\begin{array}{l}15 \text {-abr- } \\
2020\end{array}$ & Revisão & $\begin{array}{l}\text { A favor do uso de } \\
\text { máscaras em locais } \\
\text { públicos }\end{array}$ \\
\hline Cheng et al. ${ }^{40}$ & The Lancet & $\begin{array}{l}\text { Wearing face masks in the community } \\
\text { during the COVID-19 pandemic: } \\
\text { altruism and solidarity }\end{array}$ & $\begin{array}{l}16-\text {-abr- } \\
2020\end{array}$ & Comentário & $\begin{array}{l}\text { A favor do uso de } \\
\text { máscaras em locais } \\
\text { públicos }\end{array}$ \\
\hline Pleil et al. ${ }^{41}$ & $\begin{array}{l}\text { Journal of Breath } \\
\text { Research }\end{array}$ & $\begin{array}{l}\text { The scientific rationale for the use } \\
\text { of simple masks or improvised face } \\
\text { coverings to trap exhaled aerosols and } \\
\text { possibly reduce the breathborne spread } \\
\text { of COVID-19 }\end{array}$ & $\begin{array}{l}17 \text {-abr- } \\
2020\end{array}$ & Editorial & $\begin{array}{l}\text { A favor do uso de } \\
\text { máscaras em locais } \\
\text { públicos }\end{array}$ \\
\hline $\begin{array}{l}\text { Cowling et } \\
\text { al. }{ }^{42}\end{array}$ & $\begin{array}{l}\text { The Lancet Public } \\
\text { Health }\end{array}$ & $\begin{array}{l}\text { Impact assessment of non- } \\
\text { pharmaceutical interventions against } \\
\text { coronavirus disease } 2019 \text { and influenza in } \\
\text { Hong Kong: an observational study }\end{array}$ & $\begin{array}{l}17-\text { abr- } \\
2020\end{array}$ & $\begin{array}{l}\text { Estudo } \\
\text { transversal }\end{array}$ & $\begin{array}{l}\text { A favor do uso de } \\
\text { máscaras em locais } \\
\text { públicos }\end{array}$ \\
\hline $\begin{array}{l}\text { Desai e } \\
\text { Aronoff }{ }^{43}\end{array}$ & JAMA & Masks and coronavirus disease 2019 & $\begin{array}{l}17 \text {-abr- } \\
2020\end{array}$ & Comentário & $\begin{array}{l}\text { A favor do uso de } \\
\text { máscaras em locais } \\
\text { públicos }\end{array}$ \\
\hline $\begin{array}{l}\text { MacIntyre e } \\
\text { Hasanain }^{44}\end{array}$ & $\begin{array}{l}\text { Journal of Travel } \\
\text { Medicine }\end{array}$ & $\begin{array}{l}\text { Community universal face mask use } \\
\text { during the COVID } 19 \text { pandemic - from } \\
\text { households to travelers and public spaces }\end{array}$ & $\begin{array}{l}18 \text {-abr- } \\
2020\end{array}$ & $\begin{array}{l}\text { Artigo de } \\
\text { opinião }\end{array}$ & $\begin{array}{l}\text { A favor do uso de } \\
\text { máscaras em locais } \\
\text { públicos }\end{array}$ \\
\hline $\begin{array}{l}\text { Abd-Elsayed } \\
\text { e Karri }^{45}\end{array}$ & $\begin{array}{l}\text { Anesthesia and } \\
\text { Analgesia }\end{array}$ & $\begin{array}{l}\text { Utility of substandard face mask options } \\
\text { for health care workers during the } \\
\text { COVID-19 pandemic }\end{array}$ & $\begin{array}{l}20-a b r- \\
2020\end{array}$ & Revisão & $\begin{array}{l}\text { A favor do uso de } \\
\text { máscaras em locais } \\
\text { públicos }\end{array}$ \\
\hline $\begin{array}{l}\text { Eikenberry } \\
\text { et al. }{ }^{46}\end{array}$ & $\begin{array}{l}\text { Infectious Disease } \\
\text { Modelling }\end{array}$ & $\begin{array}{l}\text { To mask or not to mask: Modeling } \\
\text { the potential for face mask use by the } \\
\text { general public to curtail the COVID-19 } \\
\text { pandemic }\end{array}$ & $\begin{array}{l}21-a b r- \\
2020\end{array}$ & $\begin{array}{l}\text { Estudo } \\
\text { transversal }\end{array}$ & $\begin{array}{l}\text { A favor do uso de } \\
\text { máscaras em locais } \\
\text { públicos }\end{array}$ \\
\hline Thomson $^{47}$ & $\begin{array}{l}\text { The International } \\
\text { Journal of Clinical } \\
\text { Practice }\end{array}$ & $\begin{array}{l}\text { COVID-19: Leaving lockdown - Of } \\
\text { Schrodinger, cats, testing and masks }\end{array}$ & $\begin{array}{l}21-\text { abr- } \\
2020\end{array}$ & $\begin{array}{l}\text { Comunicação } \\
\text { breve }\end{array}$ & $\begin{array}{l}\text { A favor do uso de } \\
\text { máscaras em locais } \\
\text { públicos }\end{array}$ \\
\hline Garcia $^{48}$ & $\begin{array}{l}\text { Epidemiologia e } \\
\text { Serviços de Saúde }\end{array}$ & $\begin{array}{l}\text { Use of facemasks to limit COVID-19 } \\
\text { transmission }\end{array}$ & $\begin{array}{l}22 \text {-abr- } \\
2020\end{array}$ & $\begin{array}{l}\text { Artigo de } \\
\text { opinião }\end{array}$ & $\begin{array}{l}\text { A favor do uso de } \\
\text { máscaras em locais } \\
\text { públicos }\end{array}$ \\
\hline Chen et al. ${ }^{49}$ & $\begin{array}{l}\text { International } \\
\text { Journal of } \\
\text { Environmental } \\
\text { Research and } \\
\text { Public Health }\end{array}$ & $\begin{array}{l}\text { Hand hygiene, mask-wearing behaviors } \\
\text { and its associated factors during the } \\
\text { COVID- } 20 \text { epidemic: A cross-sectional } \\
\text { study among primary school students in } \\
\text { Wuhan, China }\end{array}$ & $\begin{array}{l}22-\text { abr- } \\
2020\end{array}$ & $\begin{array}{l}\text { Estudo } \\
\text { transversal }\end{array}$ & $\begin{array}{l}\text { A favor do uso de } \\
\text { máscaras em locais } \\
\text { públicos }\end{array}$ \\
\hline
\end{tabular}


Quadro 1. Artigos selecionados quanto ao seu posicionamento com relação ao amplo uso de máscaras de tecido.

\begin{tabular}{|c|c|c|c|c|c|}
\hline Autor(es) & Revista & Título & $\begin{array}{l}\text { Data de } \\
\text { publicação } \\
\text { (dd/mm/ } \\
\text { aa) }\end{array}$ & $\begin{array}{c}\text { Tipo de } \\
\text { publicação }\end{array}$ & $\begin{array}{c}\text { Posição relacionada } \\
\text { à adoção do uso de } \\
\text { máscara facial }\end{array}$ \\
\hline Lee e You ${ }^{50}$ & $\begin{array}{l}\text { International } \\
\text { Journal of } \\
\text { Environmental } \\
\text { Research and } \\
\text { Public Health } \\
\end{array}$ & $\begin{array}{l}\text { Psychological and behavioral responses } \\
\text { in South Korea during the early stages of } \\
\text { coronavirus disease } 2019 \text { (COVID-19) }\end{array}$ & $\begin{array}{l}22-\text { abr- } \\
2020\end{array}$ & $\begin{array}{l}\text { Estudo } \\
\text { transversal }\end{array}$ & $\begin{array}{l}\text { A favor do uso de } \\
\text { máscaras em locais } \\
\text { públicos }\end{array}$ \\
\hline $\begin{array}{l}\text { Chiang et } \\
\text { al. }^{51}\end{array}$ & \begin{tabular}{|l|} 
Emergent \\
Infectious Diseases
\end{tabular} & $\begin{array}{l}\text { The practice of wearing surgical masks } \\
\text { during the COVID-19 pandemic }\end{array}$ & $\begin{array}{l}23-\text { abr- } \\
2020\end{array}$ & $\begin{array}{l}\text { Carta ao } \\
\text { editor }\end{array}$ & $\begin{array}{l}\text { A favor do uso de } \\
\text { máscaras em locais } \\
\text { públicos }\end{array}$ \\
\hline Setti et al. ${ }^{52}$ & $\begin{array}{l}\text { International } \\
\text { Journal of } \\
\text { Environmental } \\
\text { Research and } \\
\text { Public Health } \\
\end{array}$ & $\begin{array}{l}\text { Airborne transmission route of } \\
\text { COVID-19: Why } 2 \text { meters/7 feet of inter- } \\
\text { personal distance could not be enough }\end{array}$ & $\begin{array}{l}23-\mathrm{abr}- \\
2020\end{array}$ & Editorial & $\begin{array}{l}\text { A favor do uso de } \\
\text { máscaras em locais } \\
\text { públicos }\end{array}$ \\
\hline Cheng et al. ${ }^{53}$ & $\begin{array}{l}\text { Journal of } \\
\text { Infection }\end{array}$ & $\begin{array}{l}\text { The role of community-wide wearing } \\
\text { of face mask for control of coronavirus } \\
\text { disease } 2019 \text { (COVID-19) epidemic due } \\
\text { to SARS-CoV-2 }\end{array}$ & $\begin{array}{l}23-\text { abr- } \\
2020\end{array}$ & $\begin{array}{l}\text { Estudo } \\
\text { transversal }\end{array}$ & $\begin{array}{l}\text { A favor do uso de } \\
\text { máscaras em locais } \\
\text { públicos }\end{array}$ \\
\hline Konda et al. ${ }^{54}$ & ACS nano & $\begin{array}{l}\text { Aerosol filtration efficiency of common } \\
\text { fabrics used in respiratory cloth masks. }\end{array}$ & $\begin{array}{l}24 \text {-abr- } \\
2020\end{array}$ & $\begin{array}{l}\text { Estudo } \\
\text { transversal }\end{array}$ & $\begin{array}{l}\text { A favor do uso de } \\
\text { máscaras em locais } \\
\text { públicos }\end{array}$ \\
\hline Victor et al. ${ }^{55}$ & EClinicalMedicine & $\begin{array}{l}\text { A reality check on the use of face masks } \\
\text { during the COVID-19 outbreak in Hong } \\
\text { Kong }\end{array}$ & $\begin{array}{l}24 \text {-abr- } \\
2020\end{array}$ & $\begin{array}{l}\text { Estudo } \\
\text { transversal }\end{array}$ & $\begin{array}{l}\text { A favor do uso de } \\
\text { máscaras em locais } \\
\text { públicos }\end{array}$ \\
\hline Wu e $\mathrm{Qi}^{56}$ & Genes and Diseases & $\begin{array}{l}\text { Masks and thermometers: Paramount } \\
\text { measures to stop the rapid spread of } \\
\text { SARS-CoV-3 in the United States }\end{array}$ & $\begin{array}{l}25-\mathrm{abr}- \\
2020\end{array}$ & Comentário & $\begin{array}{l}\text { A favor do uso de } \\
\text { máscaras em locais } \\
\text { públicos }\end{array}$ \\
\hline $\begin{array}{l}\text { Wilson et } \\
\text { al. }{ }^{57}\end{array}$ & $\begin{array}{l}\text { Journal of Hosp } \\
\text { Infect }\end{array}$ & $\begin{array}{l}\text { COVID-19 and non-traditional mask } \\
\text { use: How do various materials compare } \\
\text { in reducing the infection risk for mask } \\
\text { wearers? }\end{array}$ & $\begin{array}{l}26-\text {-abr- } \\
2020\end{array}$ & $\begin{array}{l}\text { Estudo } \\
\text { transversal }\end{array}$ & $\begin{array}{l}\text { A favor do uso de } \\
\text { máscaras em locais } \\
\text { públicos }\end{array}$ \\
\hline $\begin{array}{l}\text { Sunjaya e } \\
\text { Jenkins }^{58}\end{array}$ & Respirology & $\begin{array}{l}\text { Rationale for unversal face mask in public } \\
\text { against COVI-20 }\end{array}$ & $\begin{array}{l}30-\text { abr- } \\
2020\end{array}$ & Comentário & $\begin{array}{l}\text { A favor do uso de } \\
\text { máscaras em locais } \\
\text { públicos }\end{array}$ \\
\hline $\begin{array}{l}\text { Ngonghala } \\
\text { et al. } .^{59}\end{array}$ & Respirology & $\begin{array}{l}\text { Mathematical assessment of the impact } \\
\text { of non-pharmaceutical interventions on } \\
\text { curtailing the } 2020 \text { novel Coronavirus }\end{array}$ & $\begin{array}{l}30 \text {-abr- } \\
2020\end{array}$ & $\begin{array}{l}\text { Estudo } \\
\text { transversal }\end{array}$ & $\begin{array}{l}\text { A favor do uso de } \\
\text { máscaras em locais } \\
\text { públicos }\end{array}$ \\
\hline $\begin{array}{l}\text { MacIntyrea } \\
\text { e Chughtai }\end{array}$ & \begin{tabular}{|l|} 
International \\
Journal of Nursing \\
Study
\end{tabular} & $\begin{array}{l}\text { A rapid systematic review of the efficacy } \\
\text { of face masks and respirators against } \\
\text { coronaviruses and other respiratory } \\
\text { transmissible viruses for the community, } \\
\text { healthcare workers and sick patients }\end{array}$ & $\begin{array}{l}30 \text {-abr- } \\
2020\end{array}$ & $\begin{array}{l}\text { Revisão } \\
\text { sistemática }\end{array}$ & $\begin{array}{l}\text { A favor do uso de } \\
\text { máscaras em locais } \\
\text { públicos }\end{array}$ \\
\hline $\begin{array}{l}\text { Hoertel et } \\
\text { al. }{ }^{61}\end{array}$ & medRxiv preprint & $\begin{array}{l}\text { Lockdown exit strategies and risk of a } \\
\text { second epidemic peak: a stochastic agent- } \\
\text { based model of SARS-CoV-2 epidemic } \\
\text { in France }\end{array}$ & $\begin{array}{l}5 \text {-mai- } \\
2020\end{array}$ & $\begin{array}{l}\text { Estudo } \\
\text { transversal }\end{array}$ & $\begin{array}{l}\text { A favor do uso de } \\
\text { máscaras em locais } \\
\text { públicos }\end{array}$ \\
\hline $\begin{array}{l}\text { Szczesniak et } \\
\text { al. }^{62}\end{array}$ & $\begin{array}{l}\text { Brain, Behavior, } \\
\text { and Immunity }\end{array}$ & $\begin{array}{l}\text { Psychopathological responses and face } \\
\text { mask restrictions during the COVID-19 } \\
\text { outbreak: Results from a nationwide } \\
\text { survey }\end{array}$ & $\begin{array}{l}\text { 7-mai- } \\
2020\end{array}$ & $\begin{array}{l}\text { Carta ao } \\
\text { editor }\end{array}$ & $\begin{array}{l}\text { A favor do uso de } \\
\text { máscaras em locais } \\
\text { públicos }\end{array}$ \\
\hline Kang $^{63}$ & $\begin{array}{l}\text { Disaster Medicine } \\
\text { and Public Health } \\
\text { Preparedness }\end{array}$ & $\begin{array}{l}\text { Lessons learned from cases of COVID-19 } \\
\text { infection in South Korea }\end{array}$ & $\begin{array}{l}\text { 7-mai- } \\
2020\end{array}$ & $\begin{array}{l}\text { Estudo } \\
\text { transversal }\end{array}$ & $\begin{array}{l}\text { A favor do uso de } \\
\text { máscaras em locais } \\
\text { públicos }\end{array}$ \\
\hline
\end{tabular}


Quadro 1. Artigos selecionados quanto ao seu posicionamento com relação ao amplo uso de máscaras de tecido.

\begin{tabular}{|c|c|c|c|c|c|}
\hline Autor(es) & Revista & Título & $\begin{array}{l}\text { Data de } \\
\text { publicação } \\
\text { (dd/mm/ } \\
\text { aa })\end{array}$ & $\begin{array}{c}\text { Tipo de } \\
\text { publicação }\end{array}$ & $\begin{array}{c}\text { Posição relacionada } \\
\text { à adoção do uso de } \\
\text { máscara facial }\end{array}$ \\
\hline Clements $^{64}$ & $\begin{array}{l}\text { JMIR Public } \\
\text { Health and } \\
\text { Surveillance }\end{array}$ & $\begin{array}{l}\text { Knowledge and behaviors toward } \\
\text { COVID-19 among US residents during } \\
\text { the early days of the pandemic: Cross- } \\
\text { sectional online questionnaire }\end{array}$ & $\begin{array}{l}\text { 8-mai- } \\
2020\end{array}$ & $\begin{array}{l}\text { Estudo } \\
\text { transversal }\end{array}$ & $\begin{array}{l}\text { A favor do uso de } \\
\text { máscaras em locais } \\
\text { públicos }\end{array}$ \\
\hline $\begin{array}{l}\text { Esposito e } \\
\text { Principi }^{65}\end{array}$ & $\begin{array}{l}\text { European Journal } \\
\text { of Pediatrics }\end{array}$ & $\begin{array}{l}\text { To mask or not to mask children to } \\
\text { overcome COVID-19 }\end{array}$ & $\begin{array}{l}\text { 9-mai- } \\
2020\end{array}$ & Revisão & $\begin{array}{l}\text { A favor do uso de } \\
\text { máscaras em locais } \\
\text { públicos }\end{array}$ \\
\hline Parry $^{66}$ & The BMJ & $\begin{array}{l}\text { Covid-19: Hong Kong government } \\
\text { supplies reusable face masks to all } \\
\text { residents }\end{array}$ & $\begin{array}{l}11-\text { mai- } \\
2020\end{array}$ & $\begin{array}{l}\text { Comunicação } \\
\text { breve }\end{array}$ & $\begin{array}{l}\text { A favor do uso de } \\
\text { máscaras em locais } \\
\text { públicos }\end{array}$ \\
\hline Soto et al. ${ }^{67}$ & $\begin{array}{l}\text { Infection Control } \\
\text { \& Hospital } \\
\text { Epidemiology } \\
\end{array}$ & $\begin{array}{l}\text { The feasibility of generalized face mask } \\
\text { usage during the COVID-19 pandemic: a } \\
\text { perspective from Latin America }\end{array}$ & $\begin{array}{l}11-\text { mai- } \\
2020\end{array}$ & $\begin{array}{l}\text { Carta ao } \\
\text { editor }\end{array}$ & $\begin{array}{l}\text { A favor do uso de } \\
\text { máscaras em locais } \\
\text { públicos }\end{array}$ \\
\hline $\begin{array}{l}\text { Huang et } \\
\text { al. }^{68}\end{array}$ & $\begin{array}{l}\text { Journal of Medical } \\
\text { Internet Research }\end{array}$ & $\begin{array}{l}\text { Measures undertaken in China to avoid } \\
\text { COVID-19 infection: Internet-based, } \\
\text { cross-sectional survey study }\end{array}$ & $\begin{array}{l}12-\text { mai- } \\
2020\end{array}$ & $\begin{array}{l}\text { Estudo } \\
\text { transversal }\end{array}$ & $\begin{array}{l}\text { A favor do uso de } \\
\text { máscaras em locais } \\
\text { públicos }\end{array}$ \\
\hline $\begin{array}{l}\text { Harnoor et } \\
\text { al. }{ }^{9}\end{array}$ & $\begin{array}{l}\text { The Indian Journal } \\
\text { of Pediatrics }\end{array}$ & Use of face masks in COVID-19 & $\begin{array}{l}12-\text { mai- } \\
2020\end{array}$ & $\begin{array}{l}\text { Carta ao } \\
\text { editor }\end{array}$ & $\begin{array}{l}\text { A favor do uso de } \\
\text { máscaras em locais } \\
\text { públicos }\end{array}$ \\
\hline $\begin{array}{l}\text { Kashyap et } \\
\text { al. }{ }^{70}\end{array}$ & $\begin{array}{l}\text { Journal of Clinical } \\
\text { Orthopaedics and } \\
\text { Trauma }\end{array}$ & $\begin{array}{l}\text { Fast and economic cardboard cutout use } \\
\text { to increase compliance of face mask wear } \\
\text { during COVID-19 pandemic }\end{array}$ & $\begin{array}{l}\text { 13-mai- } \\
2020\end{array}$ & $\begin{array}{l}\text { Comunicação } \\
\text { breve }\end{array}$ & $\begin{array}{l}\text { A favor do uso de } \\
\text { máscaras em locais } \\
\text { públicos }\end{array}$ \\
\hline $\begin{array}{l}\text { Matusiak et } \\
\text { al. }^{71}\end{array}$ & $\begin{array}{l}\text { Dermatologic } \\
\text { Therapy }\end{array}$ & $\begin{array}{l}\text { Inconveniences due to the use of face } \\
\text { masks during the COVID } 19 \text { pandemic: } \\
\text { A survey study of } 876 \text { young people }\end{array}$ & $\begin{array}{l}\text { 14-mai- } \\
2020\end{array}$ & $\begin{array}{l}\text { Carta ao } \\
\text { editor }\end{array}$ & $\begin{array}{l}\text { A favor do uso de } \\
\text { máscaras em locais } \\
\text { públicos }\end{array}$ \\
\hline Ogoina $^{72}$ & $\begin{array}{l}\text { The American } \\
\text { Society of Tropical } \\
\text { Medicine and } \\
\text { Hygiene } \\
\end{array}$ & $\begin{array}{l}\text { COVID-19: The Need for Rational Use of } \\
\text { Face Masks in Nigeria }\end{array}$ & $\begin{array}{l}15-\text { mai- } \\
2020\end{array}$ & $\begin{array}{l}\text { Comunicação } \\
\text { breve }\end{array}$ & $\begin{array}{l}\text { A favor do uso de } \\
\text { máscaras em locais } \\
\text { públicos }\end{array}$ \\
\hline Feng et al. ${ }^{73}$ & $\begin{array}{l}\text { Journal of Aerosol } \\
\text { Science }\end{array}$ & $\begin{array}{l}\text { Influence of wind and relative humidity } \\
\text { on the social distancing effectiveness } \\
\text { to prevent COVID-19 airborne } \\
\text { transmission: A numerical study }\end{array}$ & $\begin{array}{l}18-\text { mai- } \\
2020\end{array}$ & $\begin{array}{l}\text { Estudo } \\
\text { transversal }\end{array}$ & $\begin{array}{l}\text { A favor do uso de } \\
\text { máscaras em locais } \\
\text { públicos }\end{array}$ \\
\hline Noh et al. ${ }^{74}$ & $\begin{array}{l}\text { Journal of Korean } \\
\text { Medical Science }\end{array}$ & $\begin{array}{l}\text { Social distancing against COVID-19: } \\
\text { Implication for the control of influenza }\end{array}$ & $\begin{array}{l}18 \text {-mai- } \\
2020\end{array}$ & $\begin{array}{l}\text { Comunicação } \\
\text { breve }\end{array}$ & $\begin{array}{l}\text { A favor do uso de } \\
\text { máscaras em locais } \\
\text { públicos }\end{array}$ \\
\hline Gao et al. ${ }^{75}$ & medRxiv preprint & $\begin{array}{l}\text { The epidemiological characteristics } \\
\text { of } 2019 \text { novel coronavirus diseases } \\
\text { (COVID-19) in Jingmen, Hubei, China }\end{array}$ & $\begin{array}{l}21-\text { mai- } \\
2020\end{array}$ & $\begin{array}{l}\text { Estudo } \\
\text { transversal }\end{array}$ & $\begin{array}{l}\text { A favor do uso de } \\
\text { máscaras em locais } \\
\text { públicos }\end{array}$ \\
\hline Clase et al. ${ }^{76}$ & $\begin{array}{l}\text { Annals of Internal } \\
\text { Medicine }\end{array}$ & $\begin{array}{l}\text { Cloth masks may prevent transmission } \\
\text { of COVID-19: An evidence-based, risk- } \\
\text { based approach }\end{array}$ & $\begin{array}{l}22-\text { mai- } \\
2020\end{array}$ & Revisão & $\begin{array}{l}\text { A favor do uso de } \\
\text { máscaras em locais } \\
\text { públicos }\end{array}$ \\
\hline $\begin{array}{l}\text { Chiang et } \\
\text { al. }{ }^{77}\end{array}$ & $\begin{array}{l}\text { International } \\
\text { Journal of Surgery }\end{array}$ & $\begin{array}{l}\text { Can universal masking help with our } \\
\text { recovery from the COVID-19 pandemic? }\end{array}$ & $\begin{array}{l}\text { 23-mai- } \\
2020\end{array}$ & $\begin{array}{l}\text { Carta ao } \\
\text { editor }\end{array}$ & $\begin{array}{l}\text { A favor do uso de } \\
\text { máscaras em locais } \\
\text { públicos }\end{array}$ \\
\hline Goscé et al. ${ }^{78}$ & $\begin{array}{l}\text { "Journal of } \\
\text { Infection } \\
"\end{array}$ & $\begin{array}{l}\text { Modelling SARS-COV2 spread in } \\
\text { London: Approaches to lift the lockdown }\end{array}$ & $\begin{array}{l}\text { 24-mai- } \\
2020\end{array}$ & $\begin{array}{l}\text { Estudo } \\
\text { transversal }\end{array}$ & $\begin{array}{l}\text { A favor do uso de } \\
\text { máscaras em locais } \\
\text { públicos }\end{array}$ \\
\hline $\begin{array}{l}\text { Middleton e } \\
\text { Lopes }^{79}\end{array}$ & The BMJ & $\begin{array}{l}\text { Face masks in the covid-19 crisis: caveats, } \\
\text { limits, and priorities }\end{array}$ & $\begin{array}{l}\text { 26-mai- } \\
2020\end{array}$ & $\begin{array}{l}\text { Carta ao } \\
\text { editor }\end{array}$ & $\begin{array}{l}\text { A favor do uso de } \\
\text { máscaras em locais } \\
\text { públicos }\end{array}$ \\
\hline
\end{tabular}


Quadro 1. Artigos selecionados quanto ao seu posicionamento com relação ao amplo uso de máscaras de tecido.

\begin{tabular}{|c|c|c|c|c|c|}
\hline Autor(es) & Revista & Título & \begin{tabular}{|} 
Data de \\
publicação \\
$(\mathrm{dd} / \mathrm{mm} /$ \\
aa $)$
\end{tabular} & $\begin{array}{c}\text { Tipo de } \\
\text { publicação }\end{array}$ & $\begin{array}{c}\text { Posição relacionada } \\
\text { à adoção do uso de } \\
\text { máscara facial }\end{array}$ \\
\hline $\begin{array}{l}\text { Laestadius et } \\
\text { al. }^{80}\end{array}$ & $\begin{array}{l}\text { JMIR Public } \\
\text { Health and } \\
\text { Surveillance }\end{array}$ & $\begin{array}{l}\text { Online national health agency mask } \\
\text { guidance for the public in light of } \\
\text { COVID-19: Content analysis }\end{array}$ & $\begin{array}{l}\text { 26-mai- } \\
2020\end{array}$ & $\begin{array}{l}\text { Estudo } \\
\text { transversal }\end{array}$ & $\begin{array}{l}\text { A favor do uso de } \\
\text { máscaras em locais } \\
\text { públicos }\end{array}$ \\
\hline Liang et al. ${ }^{10}$ & $\begin{array}{l}\text { Travel Medicine } \\
\text { and Infectious } \\
\text { Disease }\end{array}$ & $\begin{array}{l}\text { Efficacy of face mask in preventing } \\
\text { respiratory virus transmission: A } \\
\text { systematic review and meta-analysis }\end{array}$ & $\begin{array}{l}\text { 28-mai- } \\
2020\end{array}$ & $\begin{array}{l}\text { Revisão } \\
\text { sistemática e } \\
\text { metanálise } \\
\end{array}$ & $\begin{array}{l}\text { A favor do uso de } \\
\text { máscaras em locais } \\
\text { públicos }\end{array}$ \\
\hline $\begin{array}{l}\text { Majeed et } \\
\text { al. }^{81}\end{array}$ & The BMJ & $\begin{array}{l}\text { Can the UK emulate the South Korean } \\
\text { approach to covid-19? }\end{array}$ & $\begin{array}{l}\text { 28-mai- } \\
2020\end{array}$ & Editorial & $\begin{array}{l}\text { A favor do uso de } \\
\text { máscaras em locais } \\
\text { públicos }\end{array}$ \\
\hline Chan et al..$^{82}$ & $\begin{array}{l}\text { International } \\
\text { Journal of } \\
\text { Environmental } \\
\text { Res. Public Health }\end{array}$ & $\begin{array}{l}\text { Sociodemographic predictors of health } \\
\text { risk perception, attitude and behavior } \\
\text { practices associated with health- } \\
\text { emergency disaster risk management } \\
\text { for biological hazards: The case of } \\
\text { COVID-19 pandemic in Hong Kong, SAR } \\
\text { China }\end{array}$ & $\begin{array}{l}29-\text { mai- } \\
2020\end{array}$ & $\begin{array}{l}\text { Estudo } \\
\text { transversal }\end{array}$ & $\begin{array}{l}\text { A favor do uso de } \\
\text { máscaras em locais } \\
\text { públicos }\end{array}$ \\
\hline Han et al. ${ }^{83}$ & $\begin{array}{l}\text { Dermatologic } \\
\text { Therapy }\end{array}$ & $\begin{array}{l}\text { Increased flare of acne caused by long } \\
\text { time mask wearing during COVID } 19 \\
\text { pandemic among general population }\end{array}$ & $\begin{array}{l}29-\text { mai- } \\
2020\end{array}$ & $\begin{array}{l}\text { Carta ao } \\
\text { editor }\end{array}$ & $\begin{array}{l}\text { A favor do uso de } \\
\text { máscaras em locais } \\
\text { públicos }\end{array}$ \\
\hline Liu et al. ${ }^{84}$ & $\begin{array}{l}\text { Infectious Diseases } \\
\text { of Poverty }\end{array}$ & $\begin{array}{l}\text { Psychological status and behavior } \\
\text { changes of the public during the } \\
\text { COVID-19 epidemic in China }\end{array}$ & $\begin{array}{l}29-\text { mai- } \\
2020\end{array}$ & $\begin{array}{l}\text { Estudo } \\
\text { transversal }\end{array}$ & $\begin{array}{l}\text { A favor do uso de } \\
\text { máscaras em locais } \\
\text { públicos }\end{array}$ \\
\hline Lee et al. ${ }^{85}$ & $\begin{array}{l}\text { Clinical Infectious } \\
\text { Diseases }\end{array}$ & $\begin{array}{l}\text { Impact of public health interventions } \\
\text { on seasonal influenza activity during the } \\
\text { SARS-CoV-2 outbreak in Korea }\end{array}$ & $\begin{array}{l}\text { 30-mai- } \\
2020\end{array}$ & $\begin{array}{l}\text { Estudo } \\
\text { transversal }\end{array}$ & $\begin{array}{l}\text { A favor do uso de } \\
\text { máscaras em locais } \\
\text { públicos }\end{array}$ \\
\hline Chu et al. ${ }^{86}$ & The Lancet & $\begin{array}{l}\text { Physical distancing, face masks, and } \\
\text { eye protection to prevent person-to- } \\
\text { person transmission of SARS-CoV-2 } \\
\text { and COVID-19: A systematic review and } \\
\text { meta-analysis }\end{array}$ & $\begin{array}{l}1-\text { jun- } \\
2020\end{array}$ & $\begin{array}{l}\text { Revisão } \\
\text { sistemática e } \\
\text { metanálise }\end{array}$ & $\begin{array}{l}\text { A favor do uso de } \\
\text { máscaras em locais } \\
\text { públicos }\end{array}$ \\
\hline $\mathrm{Liu}^{87}$ & $\begin{array}{l}\text { Cyberpsychology, } \\
\text { behavior, and } \\
\text { social networking }\end{array}$ & $\begin{array}{l}\text { COVID-19 information seeking on } \\
\text { digital media and preventive behaviors: } \\
\text { The mediation role of worry }\end{array}$ & $\begin{array}{l}4 \text {-jun- } \\
2020\end{array}$ & $\begin{array}{l}\text { Estudo } \\
\text { transversal }\end{array}$ & $\begin{array}{l}\text { A favor do uso de } \\
\text { máscaras em locais } \\
\text { públicos }\end{array}$ \\
\hline Jung et al. ${ }^{88}$ & $\begin{array}{l}\text { Clinical } \\
\text { hemorheology and } \\
\text { microcirculation }\end{array}$ & $\begin{array}{l}\text { How we should respond to the } \\
\text { Coronavirus SARS-CoV-2 outbreak: A } \\
\text { German perspective }\end{array}$ & $\begin{array}{l}5 \text {-jun- } \\
2020\end{array}$ & $\begin{array}{l}\text { Estudo } \\
\text { transversal }\end{array}$ & $\begin{array}{l}\text { A favor do uso de } \\
\text { máscaras em locais } \\
\text { públicos }\end{array}$ \\
\hline Li et al. ${ }^{89}$ & Oral Diseases & $\begin{array}{l}\text { Facial protection in the era of COVID 19: } \\
\text { A narrative review }\end{array}$ & $\begin{array}{l}7 \text {-jun- } \\
2020\end{array}$ & Revisão & $\begin{array}{l}\text { A favor do uso de } \\
\text { máscaras em locais } \\
\text { públicos }\end{array}$ \\
\hline Goh et al..$^{90}$ & $\begin{array}{l}\text { Brain, Behavior, } \\
\text { and Immunity }\end{array}$ & $\begin{array}{l}\text { The face mask: How a real protection } \\
\text { becomes a psychological symbol during } \\
\text { Covid-19? }\end{array}$ & $\begin{array}{l}8 \text {-jun- } \\
2020\end{array}$ & Revisão & $\begin{array}{l}\text { A favor do uso de } \\
\text { máscaras em locais } \\
\text { públicos }\end{array}$ \\
\hline Greenhalgh $^{91}$ & The BMJ & $\begin{array}{l}\text { Laying straw men to rest: author's reply } \\
\text { to "Urgency and uncertainty: covid-19, } \\
\text { face masks, and evidence informed } \\
\text { policy" }\end{array}$ & $\begin{array}{l}8 \text {-jun- } \\
2020\end{array}$ & $\begin{array}{l}\text { Carta ao } \\
\text { editor }\end{array}$ & $\begin{array}{l}\text { A favor do uso de } \\
\text { máscaras em locais } \\
\text { públicos }\end{array}$ \\
\hline Wong et al. ${ }^{92}$ & $\begin{array}{l}\text { Transboundary } \\
\text { Emerging Disease }\end{array}$ & $\begin{array}{l}\text { Uncovering psychobehavioral } \\
\text { implications of SARS-CoV-2 infection } \\
\text { in Iran }\end{array}$ & $\begin{array}{l}8 \text {-jun- } \\
2020\end{array}$ & $\begin{array}{l}\text { Estudo } \\
\text { transversal }\end{array}$ & $\begin{array}{l}\text { A favor do uso de } \\
\text { máscaras em locais } \\
\text { públicos }\end{array}$ \\
\hline
\end{tabular}


Quadro 1. Artigos selecionados quanto ao seu posicionamento com relação ao amplo uso de máscaras de tecido.

\begin{tabular}{|c|c|c|c|c|c|}
\hline Autor(es) & Revista & Título & $\begin{array}{l}\text { Data de } \\
\text { publicação } \\
\text { (dd/mm/ } \\
\text { aa) }\end{array}$ & $\begin{array}{c}\text { Tipo de } \\
\text { publicação }\end{array}$ & $\begin{array}{c}\text { Posição relacionada } \\
\text { à adoção do uso de } \\
\text { máscara facial }\end{array}$ \\
\hline Zhang et al..$^{93}$ & $\begin{array}{l}\text { Proceedings of the } \\
\text { National Academy } \\
\text { of Science of the } \\
\text { United States of } \\
\text { America - PNAS }\end{array}$ & $\begin{array}{l}\text { Identifying airborne transmission as } \\
\text { the dominant route for the spread of } \\
\text { COVID-19 }\end{array}$ & $\begin{array}{l}11-\text { jun- } \\
2020\end{array}$ & $\begin{array}{l}\text { Estudo } \\
\text { transversal }\end{array}$ & $\begin{array}{l}\text { A favor do uso de } \\
\text { máscaras em locais } \\
\text { públicos }\end{array}$ \\
\hline Ho et al. ${ }^{94}$ & $\begin{array}{l}\text { Science of The } \\
\text { Total Environment }\end{array}$ & $\begin{array}{l}\text { Medical mask versus cotton mask } \\
\text { for preventing respiratory droplet } \\
\text { transmission in micro environments }\end{array}$ & $\begin{array}{l}11 \text {-jun- } \\
2020\end{array}$ & $\begin{array}{l}\text { Comunicação } \\
\text { breve }\end{array}$ & $\begin{array}{l}\text { A favor do uso de } \\
\text { máscaras em locais } \\
\text { públicos }\end{array}$ \\
\hline $\begin{array}{l}\text { Esposito et } \\
\text { al. } .5\end{array}$ & $\begin{array}{l}\text { European } \\
\text { Respiratory } \\
\text { Journal }\end{array}$ & $\begin{array}{l}\text { Universal use of face masks for success } \\
\text { against COVID-19: Evidence and } \\
\text { implications for prevention policies }\end{array}$ & $\begin{array}{l}18 \text {-jun- } \\
2020\end{array}$ & Revisão & $\begin{array}{l}\text { A favor do uso de } \\
\text { máscaras em locais } \\
\text { públicos }\end{array}$ \\
\hline Dkhar et al. ${ }^{96}$ & $\begin{array}{l}\text { Indian Journal of } \\
\text { Public Health }\end{array}$ & $\begin{array}{l}\text { Knowledge, attitude, and practices related } \\
\text { to COVID-19 pandemic among social } \\
\text { media users in J\&K, India }\end{array}$ & $\begin{array}{l}\text { 19-jun- } \\
2020\end{array}$ & $\begin{array}{l}\text { Estudo } \\
\text { transversal }\end{array}$ & $\begin{array}{l}\text { A favor do uso de } \\
\text { máscaras em locais } \\
\text { públicos }\end{array}$ \\
\hline Wang et al. ${ }^{20}$ & $\begin{array}{l}\text { European Review } \\
\text { for Medical and } \\
\text { Pharmacological } \\
\text { Sciences }\end{array}$ & $\begin{array}{l}\text { Mask crisis during the COVID-19 } \\
\text { outbreak }\end{array}$ & $\begin{array}{l}3-\text { jan- } \\
2020\end{array}$ & $\begin{array}{l}\text { Artigo de } \\
\text { opinião }\end{array}$ & $\begin{array}{l}\text { Sem posicionamento } \\
\text { claro quanto ao uso } \\
\text { de máscaras em } \\
\text { locais públicos }\end{array}$ \\
\hline Feng et al. ${ }^{21}$ & $\begin{array}{l}\text { The Lancet } \\
\text { Respiratory } \\
\text { Medicine }\end{array}$ & $\begin{array}{l}\text { Rational use of face masks in the } \\
\text { COVID-19 pandemic }\end{array}$ & $\begin{array}{l}5-j a n- \\
2020\end{array}$ & Comentário & $\begin{array}{l}\text { Sem posicionamento } \\
\text { claro quanto ao uso } \\
\text { de máscaras em } \\
\text { locais públicos }\end{array}$ \\
\hline Wu et al. ${ }^{101}$ & EClinicalMedicine & $\begin{array}{l}\text { Facemask shortage and the novel } \\
\text { coronavirus disease (COVID-19) } \\
\text { outbreak: Reflections on public health } \\
\text { measures }\end{array}$ & $\begin{array}{l}4-\mathrm{mar}- \\
2020\end{array}$ & Revisão & $\begin{array}{l}\text { Sem posicionamento } \\
\text { claro quanto ao uso } \\
\text { de máscaras em } \\
\text { locais públicos }\end{array}$ \\
\hline Stone $^{102}$ & $\begin{array}{l}\text { Nursing Health } \\
\text { and Science }\end{array}$ & $\begin{array}{l}\text { Editorial: Facemasks and the Covid- } 19 \\
\text { pandemic: What advice should health } \\
\text { professionals be giving the general public } \\
\text { about the wearing of facemasks? }\end{array}$ & $\begin{array}{l}12-\text { abr- } \\
2020\end{array}$ & Editorial & $\begin{array}{l}\text { Sem posicionamento } \\
\text { claro quanto ao uso } \\
\text { de máscaras em } \\
\text { locais públicos }\end{array}$ \\
\hline $\begin{array}{l}\text { Chowdhury } \\
\text { et al. }{ }^{103}\end{array}$ & Virusdisease & $\begin{array}{l}\text { One month of the novel coronavirus } \\
2019 \text { outbreak: Is it still a threat? }\end{array}$ & $\begin{array}{l}20-\text { abr- } \\
2020\end{array}$ & Revisão & $\begin{array}{l}\text { Sem posicionamento } \\
\text { claro quanto ao uso } \\
\text { de máscaras em } \\
\text { locais públicos }\end{array}$ \\
\hline $\begin{array}{l}\text { Amendola et } \\
\text { al. }^{104}\end{array}$ & $\begin{array}{l}\text { Microchemical } \\
\text { Journal }\end{array}$ & $\begin{array}{l}\text { A rapid screening method for testing the } \\
\text { efficiency of masks in breaking down } \\
\text { aerosols }\end{array}$ & $\begin{array}{l}3-\text { mai- } \\
2020\end{array}$ & $\begin{array}{l}\text { Estudo } \\
\text { transversal }\end{array}$ & $\begin{array}{l}\text { Sem posicionamento } \\
\text { claro quanto ao uso } \\
\text { de máscaras em } \\
\text { locais públicos }\end{array}$ \\
\hline $\operatorname{Kim}^{105}$ & $\begin{array}{l}\text { Journal of Korean } \\
\text { Medical Science }\end{array}$ & $\begin{array}{l}\text { What type of face mask is appropriate for } \\
\text { everyone-mask-wearing policy amidst } \\
\text { COVID-19 pandemic? }\end{array}$ & $\begin{array}{l}8-\mathrm{mai}- \\
2020\end{array}$ & Revisão & $\begin{array}{l}\text { Sem posicionamento } \\
\text { claro quanto ao uso } \\
\text { de máscaras em } \\
\text { locais públicos }\end{array}$ \\
\hline Lam et al. ${ }^{106}$ & $\begin{array}{l}\text { International } \\
\text { Journal of Nursing } \\
\text { Studies }\end{array}$ & $\begin{array}{l}\text { Uncertainty surrounding the use of } \\
\text { face masks in the community amid the } \\
\text { COVID-19 pandemic }\end{array}$ & $\begin{array}{l}20-\text { mai- } \\
2020\end{array}$ & $\begin{array}{l}\text { Carta ao } \\
\text { editor }\end{array}$ & $\begin{array}{l}\text { Sem posicionamento } \\
\text { claro quanto ao uso } \\
\text { de máscaras em } \\
\text { locais públicos }\end{array}$ \\
\hline King $^{107}$ & The BMJ & $\begin{array}{l}\text { Covid-19: face masks could foster distrust } \\
\text { and blame }\end{array}$ & $\begin{array}{l}20-\text { mai- } \\
2020\end{array}$ & $\begin{array}{l}\text { Carta ao } \\
\text { editor }\end{array}$ & $\begin{array}{l}\text { Sem posicionamento } \\
\text { claro quanto ao uso } \\
\text { de máscaras em } \\
\text { locais públicos }\end{array}$ \\
\hline
\end{tabular}


Quadro 1. Artigos selecionados quanto ao seu posicionamento com relação ao amplo uso de máscaras de tecido.

\begin{tabular}{|c|c|c|c|c|c|}
\hline Autor(es) & Revista & Título & $\begin{array}{c}\text { Data de } \\
\text { publicação } \\
(\mathrm{dd} / \mathrm{mm} / \\
\text { aa })\end{array}$ & $\begin{array}{c}\text { Tipo de } \\
\text { publicação }\end{array}$ & $\begin{array}{c}\text { Posição relacionada } \\
\text { à adoção do uso de } \\
\text { máscara facial }\end{array}$ \\
\hline Cheng $^{108}$ & The BMJ & $\begin{array}{l}\text { Covid-19: are face masks a good long } \\
\text { term strategy? }\end{array}$ & $\begin{array}{l}20-\text { mai- } \\
2020\end{array}$ & $\begin{array}{l}\text { Carta ao } \\
\text { editor }\end{array}$ & $\begin{array}{l}\text { Sem posicionamento } \\
\text { claro quanto ao uso } \\
\text { de máscaras em } \\
\text { locais públicos }\end{array}$ \\
\hline $\begin{array}{l}\text { Lazzarino et } \\
\text { al. }{ }^{109}\end{array}$ & The BMJ & $\begin{array}{l}\text { Covid-19: Important potential side } \\
\text { effects of wearing face masks that we } \\
\text { should bear in mind }\end{array}$ & $\begin{array}{l}\text { 21-mai- } \\
2020\end{array}$ & $\begin{array}{l}\text { Carta ao } \\
\text { editor }\end{array}$ & $\begin{array}{l}\text { Sem posicionamento } \\
\text { claro quanto ao uso } \\
\text { de máscaras em } \\
\text { locais públicos }\end{array}$ \\
\hline Schroter ${ }^{110}$ & The BMJ & $\begin{array}{l}\text { Social distancing for COVID-19: is } 2 \\
\text { metres far enough? }\end{array}$ & $\begin{array}{l}\text { 21-mai- } \\
2020\end{array}$ & $\begin{array}{l}\text { Carta ao } \\
\text { editor }\end{array}$ & $\begin{array}{l}\text { Sem posicionamento } \\
\text { claro quanto ao uso } \\
\text { de máscaras em } \\
\text { locais públicos } \\
\end{array}$ \\
\hline Azlan et al. ${ }^{111}$ & Plos One & $\begin{array}{l}\text { Public knowledge, attitudes and practices } \\
\text { towards COVID-19: A cross-sectional } \\
\text { study in Malaysia }\end{array}$ & $\begin{array}{l}\text { 21-mai- } \\
2020\end{array}$ & $\begin{array}{l}\text { Estudo } \\
\text { transversal }\end{array}$ & $\begin{array}{l}\text { Sem posicionamento } \\
\text { claro quanto ao uso } \\
\text { de máscaras em } \\
\text { locais públicos }\end{array}$ \\
\hline $\begin{array}{l}\text { Szepietowski } \\
\text { et al. }{ }^{112}\end{array}$ & $\begin{array}{l}\text { Acta Derm } \\
\text { Venereologica }\end{array}$ & $\begin{array}{l}\text { Face mask-induced itch: A self- } \\
\text { questionnaire study of 2,315 responders } \\
\text { during the COVID-19 pandemic }\end{array}$ & $\begin{array}{l}25-\text { mai- } \\
2020\end{array}$ & $\begin{array}{l}\text { Estudo } \\
\text { transversal }\end{array}$ & $\begin{array}{l}\text { Sem posicionamento } \\
\text { claro quanto ao uso } \\
\text { de máscaras em } \\
\text { locais públicos }\end{array}$ \\
\hline $\begin{array}{l}\text { Aggarwal et } \\
\text { al. }{ }^{113}\end{array}$ & $\begin{array}{l}\text { Indian Journal of } \\
\text { Public Health }\end{array}$ & $\begin{array}{l}\text { Facemasks for prevention of viral } \\
\text { respiratory infections in community } \\
\text { settings: A systematic review and meta- } \\
\text { analysis }\end{array}$ & $\begin{array}{l}2 \text {-jun- } \\
2020\end{array}$ & $\begin{array}{l}\text { Revisão } \\
\text { sistemática e } \\
\text { metanálise }\end{array}$ & $\begin{array}{l}\text { Sem posicionamento } \\
\text { claro quanto ao uso } \\
\text { de máscaras em } \\
\text { locais públicos }\end{array}$ \\
\hline Zhao et al. ${ }^{114}$ & Nano letters & $\begin{array}{l}\text { Household materials selection for } \\
\text { homemade cloth face coverings and their } \\
\text { filtration efficiency enhancement with } \\
\text { triboelectric charging }\end{array}$ & $\begin{array}{l}2-\text { jun- } \\
2020\end{array}$ & $\begin{array}{l}\text { Carta ao } \\
\text { editor }\end{array}$ & $\begin{array}{l}\text { Sem posicionamento } \\
\text { claro quanto ao uso } \\
\text { de máscaras em } \\
\text { locais públicos }\end{array}$ \\
\hline $\begin{array}{l}\text { Garcia Filho } \\
\text { et al. }{ }^{115}\end{array}$ & $\begin{array}{l}\text { Epidemiol. Serv. } \\
\text { Saude }\end{array}$ & $\begin{array}{l}\text { Internet searches for measures to address } \\
\text { COVID-19 in Brazil: a description of } \\
\text { searches in the first } 100 \text { days of } 2020\end{array}$ & $\begin{array}{l}8 \text {-jun- } \\
2020\end{array}$ & $\begin{array}{l}\text { Estudo } \\
\text { transversal }\end{array}$ & $\begin{array}{l}\text { Sem posicionamento } \\
\text { claro quanto ao uso } \\
\text { de máscaras em } \\
\text { locais públicos } \\
\end{array}$ \\
\hline Mahase $^{97}$ & The BMJ & $\begin{array}{l}\text { Covid-19: What is the evidence for cloth } \\
\text { masks? }\end{array}$ & $\begin{array}{l}\text { 7-abr- } \\
2020\end{array}$ & $\begin{array}{l}\text { Artigo de } \\
\text { opinião }\end{array}$ & $\begin{array}{l}\text { Contra o uso de } \\
\text { máscaras em locais } \\
\text { públicos }\end{array}$ \\
\hline $\begin{array}{l}\text { Szarpak et } \\
\text { al. }^{98}\end{array}$ & Cardiology Journal & $\begin{array}{l}\text { Cloth masks versus medical masks for } \\
\text { COVID-19 protection }\end{array}$ & $\begin{array}{l}10-\text { abr- } \\
2020\end{array}$ & $\begin{array}{l}\text { Carta ao } \\
\text { editor }\end{array}$ & $\begin{array}{l}\text { Contra o uso de } \\
\text { máscaras em locais } \\
\text { públicos }\end{array}$ \\
\hline $\begin{array}{l}\text { Lazcano- } \\
\text { Ponce e } \\
\text { Alpunche- } \\
\text { Aranda }^{99}\end{array}$ & $\begin{array}{l}\text { Salud Publica de } \\
\text { Mexico }\end{array}$ & $\begin{array}{l}\text { [Public health literacy in the face of the } \\
\text { Covid-19 pandemic emergency] }\end{array}$ & $\begin{array}{l}18-\text {-abr- } \\
2020\end{array}$ & Editorial & $\begin{array}{l}\text { Contra o uso de } \\
\text { máscaras em locais } \\
\text { públicos }\end{array}$ \\
\hline $\begin{array}{l}\text { Martin et } \\
\text { al. }^{100}\end{array}$ & The BMJ & $\begin{array}{l}\text { "Face masks for the public during } \\
\text { COVID-19 urgency and uncertainty: } \\
\text { COVID-19, face masks, and evidence } \\
\text { informed policy" }\end{array}$ & $\begin{array}{l}\text { 26-mai- } \\
2020\end{array}$ & $\begin{array}{l}\text { Carta ao } \\
\text { editor }\end{array}$ & $\begin{array}{l}\text { Contra o uso de } \\
\text { máscaras em locais } \\
\text { públicos }\end{array}$ \\
\hline
\end{tabular}




\section{Resultados}

A seguir são apresentados os resultados desta revisão narrativa, que não propôs fornecer uma descrição detalhada e exaustiva da literatura, mas sim explorar criticamente um tema ainda pouco conhecido.

A busca resultou em 450 artigos, dos quais $93^{10,20,21,26-115}$ cumpriram os critérios de inclusão e foram selecionados para inclusão nesta revisão (Figura 1).

Os manuscritos selecionados foram classificados de acordo com o mês e tipo de publicação científica (Figura 2). Os meses de abril $(\mathrm{n}=33)^{33-}$ 37,39-47,49-60,97-99, 102,103,115 e maio $(\mathrm{n}=35)^{10,42,61-82,84,100,104-}$ ${ }^{112,116}$ concentraram o maior número de publicações, sendo os artigos de opinião, editoriais ou comentários os mais predominantes até abril $(n=25)$, enquanto os estudos transversais tornaram-se mais frequentes após essa data (Figura 2). Dos artigos selecionados, $49,5 \%$ são artigos de opinião, comentários, cartas e editoriais; $34,4 \%$, estudos transversais; e 16,1\%, revisões sistemáticas e metanálises ${ }^{10,28,39,45,60,65,76,86,89,90,95,101,103,105,113}$ (Figura 2).

Os artigos também foram classificados quanto ao seu posicionamento com relação ao amplo uso de máscaras de tecido (Figura 3). Dos artigos incluídos ( $\mathrm{n}=93), 77,4 \%(\mathrm{n}=72)$ se posicionaram a favor do amplo uso de máscaras de tecido no contexto da COVID-19 $9^{10,26-96}$ e 4,3\% $(n=4)^{97-100}$ se posicionaram contra o seu uso. É importante destacar que todos os artigos que se posiciona- ram contra o uso de máscaras eram artigos de opinião, comentários, cartas ou editoriais. Entre aqueles que se posicionaram a favor, destacamse os estudos transversais $(\mathrm{n}=28)^{18,27,33,42,46,49,50,53-}$ $55,57,59,61,63,64,66,73,75,78,80,82,84,85,87,88,92,93,96$ e as revisões de literatura $(\mathrm{n}=10)^{10,28,39,45,60,65,76,86,89,90,95}$, considerando um universo de 32 e 15 estudos, respectivamente (Quadro 1). As primeiras publicações sobre o tema estavam divididas entre as possíveis implicações do uso universal de máscaras na redução dos estoques de máscaras descartáveis e a recomendação do uso de máscaras de tecido como medida adicional na contenção da pandemia. A partir de abril, as publicações que recomendavam a adoção do uso universal de máscaras, em especial as de tecido, aumentaram de $9,72 \%(n=7)^{18,26-31}$ para $90,28 \%(n=65)^{10,33-96}$. Essa diferença também pode ser observada entre os países (Figura 4), que passaram a recomendar intensamente o uso de máscaras em ambiente extradomiciliar a partir do mês de abril (as datas da regulamentação podem ser consultadas na Tabela 1).

\section{Evolução das recomendações sobre o uso de máscaras para o controle da COVID-19 ao longo do curso da epidemia}

Com o avanço da pandemia de COVID-19, discussões sobre o uso de máscaras em ambientes extradomiciliares como intervenção em saúde pública emergiram, com posições favoráveis ${ }^{10,18,20,26-31,34,35,37,39-82,84-96,102,103,116-120}$ e contrá-

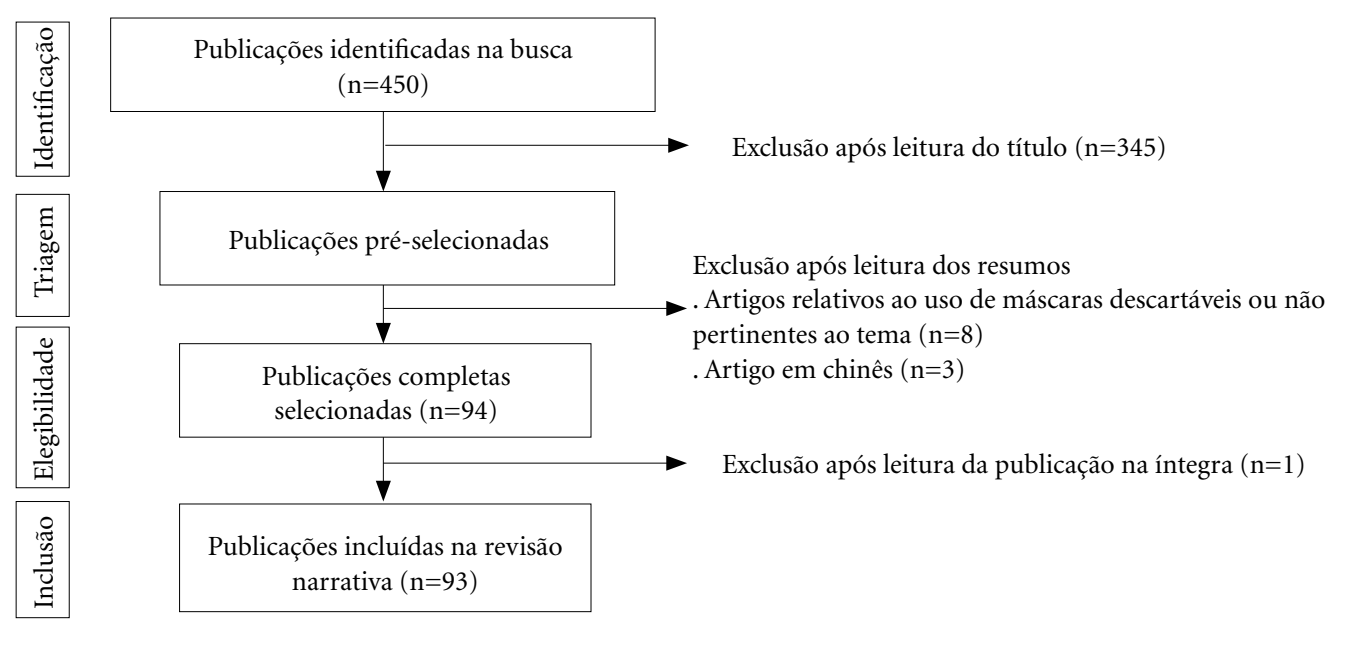

Figura 1. Fluxograma ilustrando o processo de seleção dos artigos incluídos nesta revisão narrativa. 


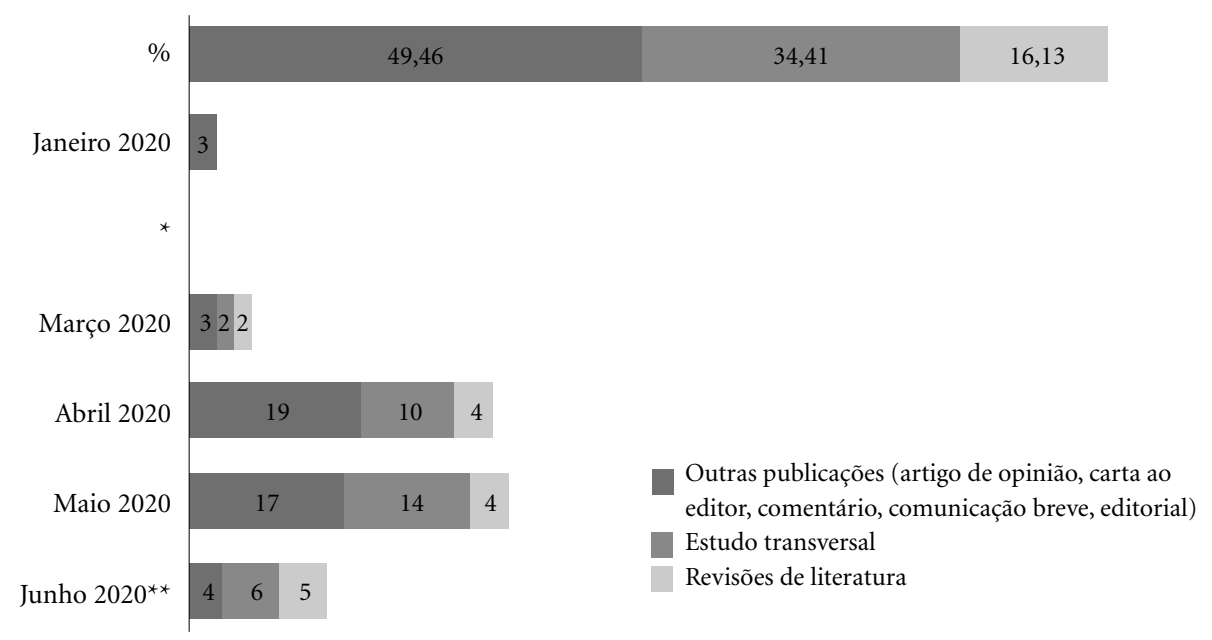

* Nenhum dos estudos selecionados foi publicado no mês de Fevereiro

${ }^{* *}$ A busca incluiu artigos disponíveis apenas até o dia 12 de junho de 2020

Figura 2. Tipos de publicações científicas sobre uso de máscaras de tecido no combate à pandemia por mês de publicação.

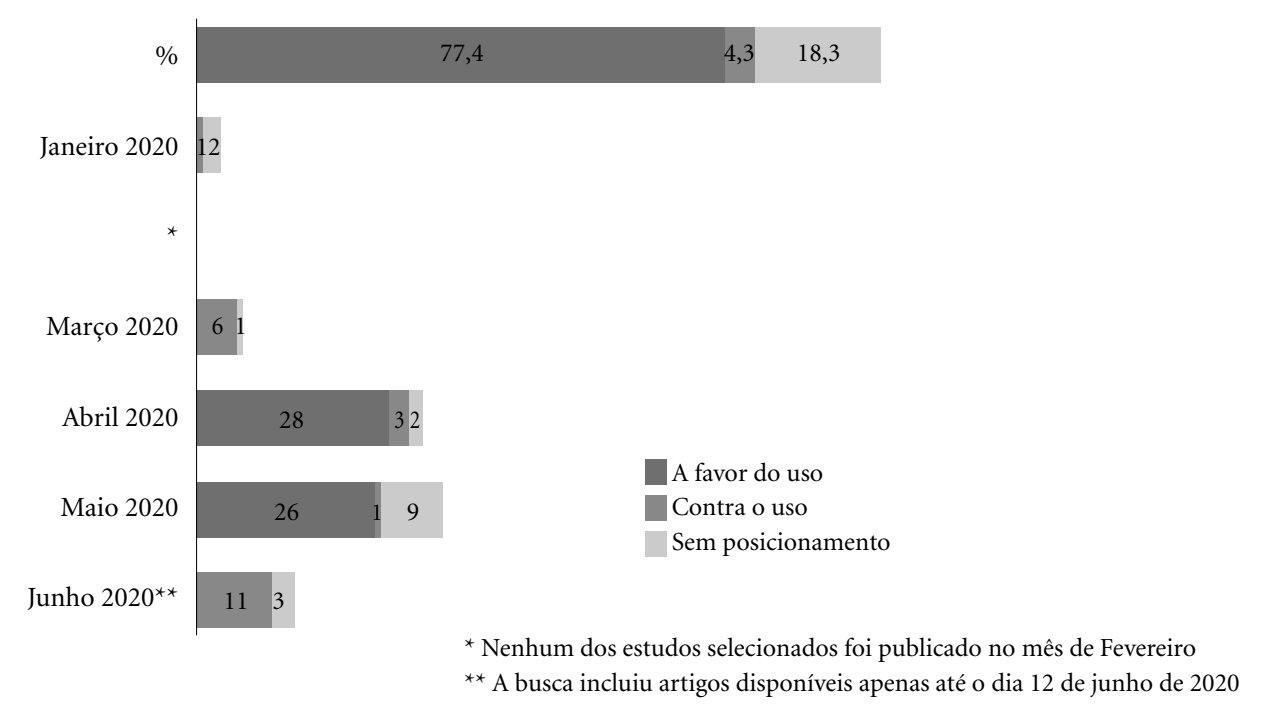

Figura 3. Posicionamentos das publicações científicas sobre o amplo uso de máscaras de tecido no combate à pandemia por mês de publicação.

rias $^{97-100}$. Posições contrárias ao amplo uso de máscaras ${ }^{97-100} \mathrm{em}$ ambientes públicos, foram observadas, sobretudo, até a primeira semana de março, baseadas nas suposições de que i) essa recomendação poderia afrouxar as medidas de dis- tanciamento social adotadas pela população ${ }^{9,121}$; ii) a manipulação e o uso inadequados das máscaras poderia elevar o risco de transmissão do novo coronavírus $^{122}$; iii) o crescimento da demanda poderia agravar a escassez de máscaras cirúrgi- 


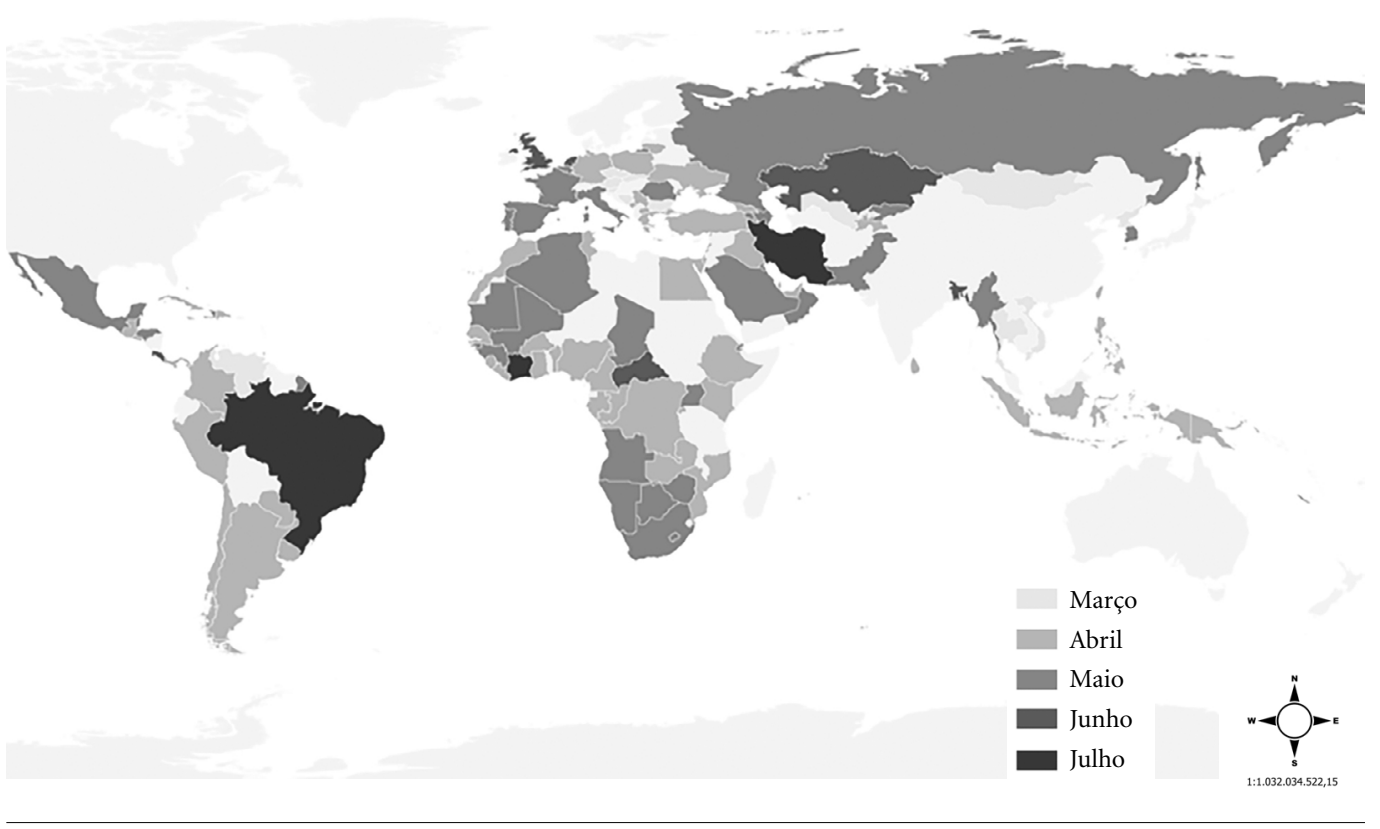

Figura 4. Países que regulamentaram o uso de máscaras em ambiente extradomiciliar desde o início da pandemia.

Fonte: Adaptado do site Mask4All (https://masks4all.co/pt/).

Tabela 1. Sequência cronológica dos países que decretaram oficialmente a utilização de máscaras faciais em locais públicos*.

\begin{tabular}{lc}
\hline \multicolumn{1}{c}{ País } & Data da requisição \\
\hline Mongólia & Março \\
Vietnã & $14 / 03 / 2020$ \\
República Tcheca & $16 / 03 / 2020$ \\
Venezuela & $18 / 03 / 2020$ \\
Coreia do Norte & $18 / 03 / 2020$ \\
Uzbequistão & $19 / 03 / 2020$ \\
Eslováquia & $22 / 03 / 2020$ \\
Tailândia & $25 / 03 / 2020$ \\
Bósnia-Herzegovina & $25 / 03 / 2020$ \\
Eslovênia & $29 / 03 / 2020$ \\
Áustria & $29 / 03 / 2020$ \\
Bulgária & $30 / 03 / 2020$ \\
\hline
\end{tabular}

continua

cas para profissionais de saúde ${ }^{18,21,69,121,123,124}$; e iv) essa recomendação poderia oportunizar a prática de preços abusivos. Reforçamos que as posições contrárias são embasadas exclusivamente em
Tabela 1. Sequência cronológica dos países que decretaram oficialmente a utilização de máscaras faciais em locais públicos*.

\begin{tabular}{lc}
\hline \multicolumn{1}{c}{ País } & Data da requisição \\
\hline & Abril \\
Israel & $01 / 04 / 2020$ \\
Taiwan & $01 / 04 / 2020$ \\
Cuba & $02 / 04 / 2020$ \\
Filipinas & $02 / 04 / 2020$ \\
Turquia & $03 / 04 / 2020$ \\
Colômbia & $04 / 04 / 2020$ \\
Indonésia & $05 / 04 / 2020$ \\
Quênia & $05 / 04 / 2020$ \\
Antígua e Barbuda & $06 / 04 / 2020$ \\
Trinidad e Tobago & $06 / 04 / 2020$ \\
Peru & $07 / 04 / 2020$ \\
Ucrânia & $07 / 04 / 2020$ \\
\hline
\end{tabular}

artigos de opinião, comentários e editoriais, os quais não apresentam evidências científicas que mostrassem a não eficácia do uso de máscaras para contenção da disseminação da doença ${ }^{97-100}$. 
Tabela 1. Sequência cronológica dos países que decretaram oficialmente a utilização de máscaras faciais em locais públicos ${ }^{\star}$.

\begin{tabular}{|c|c|}
\hline País & Data da requisição \\
\hline Marrocos & $07 / 04 / 2020$ \\
\hline Panamá & $07 / 04 / 2020$ \\
\hline Tunísia & $07 / 04 / 2020$ \\
\hline Benin & $08 / 04 / 2020$ \\
\hline Chile & $08 / 04 / 2020$ \\
\hline El Salvador & $08 / 04 / 2020$ \\
\hline Equador & $08 / 04 / 2020$ \\
\hline Moçambique & $08 / 04 / 2020$ \\
\hline Barém & $09 / 04 / 2020$ \\
\hline Gabão & $10 / 04 / 2020$ \\
\hline Lituânia & $10 / 04 / 2020$ \\
\hline Sri Lanka & $11 / 04 / 2020$ \\
\hline Etiópia & $11 / 04 / 2020$ \\
\hline Guatemala & $12 / 04 / 2020$ \\
\hline Honduras & $13 / 04 / 2020$ \\
\hline Camarões & $14 / 04 / 2020$ \\
\hline Singapura & $14 / 04 / 2020$ \\
\hline Polônia & $16 / 04 / 2020$ \\
\hline Andorra & $18 / 04 / 2020$ \\
\hline Guiné & $18 / 04 / 2020$ \\
\hline República Dominicana & $18 / 04 / 2020$ \\
\hline Zâmbia & $18 / 04 / 2020$ \\
\hline Bahamas & $19 / 04 / 2020$ \\
\hline Libéria & $19 / 04 / 2020$ \\
\hline Ruanda & $19 / 04 / 2020$ \\
\hline Argentina & $20 / 04 / 2020$ \\
\hline Georgia & $20 / 04 / 2020$ \\
\hline Iraque & $20 / 04 / 2020$ \\
\hline Luxemburgo & $20 / 04 / 2020$ \\
\hline Paraguai & $20 / 04 / 2020$ \\
\hline Senegal & $20 / 04 / 2020$ \\
\hline Jamaica & $22 / 04 / 2020$ \\
\hline Macedônia (Norte) & $22 / 04 / 2020$ \\
\hline Qatar & $22 / 04 / 2020$ \\
\hline São Tomé e Príncipe & $22 / 04 / 2020$ \\
\hline Serra Leoa & $22 / 04 / 2020$ \\
\hline Gana & $23 / 04 / 2020$ \\
\hline Uruguai & $23 / 04 / 2020$ \\
\hline Ilhas Maurício & $24 / 04 / 2020$ \\
\hline Egito & $26 / 04 / 2020$ \\
\hline Timor Leste & $26 / 04 / 2020$ \\
\hline Alemanha & $27 / 04 / 2020$ \\
\hline Burkina Faso & $27 / 04 / 2020$ \\
\hline Granada & $27 / 04 / 2020$ \\
\hline Grécia & $27 / 04 / 2020$ \\
\hline Líbano & $27 / 04 / 2020$ \\
\hline Emirados Árabes Unidos & $28 / 04 / 2020$ \\
\hline Nigéria & $28 / 04 / 2020$ \\
\hline Sérvia & $29 / 04 / 2020$ \\
\hline
\end{tabular}

Tabela 1. Sequência cronológica dos países que decretaram oficialmente a utilização de máscaras faciais em locais públicos*.

\begin{tabular}{|c|c|}
\hline País & Data da requisição \\
\hline Montenegro & $30 / 04 / 2020$ \\
\hline Congo (Congo-Brazzaville) & $30 / 04 / 2020$ \\
\hline São Cristóvão e Névis & $30 / 04 / 2020$ \\
\hline Tajiquistão & $30 / 04 / 2020$ \\
\hline
\end{tabular}

África do Sul

Maio

Azerbaijão

Belize

Botsuana

Malta

Zimbábue

Espanha

Guiné Equatorial

Namíbia

Honduras

Omã

Itália

Portugal

Cabo Verde

Lesoto

Bélgica

Mauritânia

Uganda

Chade

Moldova

Mônaco

Letônia

Sudão do Sul

Angola

Djibuti

França

Dominica

Haiti

Quirguistão

Rússia

Barbados

Kuwait

Mianmar (antiga

Birmânia)

Santa Lúcia

Guiné-Bissau

Romênia

Argélia

Armênia

Mali

México

Coreia do Sul

Arábia Saudita

Paquistão
01/05/2020

$01 / 05 / 2020$

$01 / 05 / 2020$

$01 / 05 / 2020$

$01 / 05 / 2020$

$01 / 05 / 2020$

$02 / 05 / 2020$

$02 / 05 / 2020$

$02 / 05 / 2020$

03/05/2020

$03 / 05 / 2020$

$04 / 05 / 2020$

$04 / 05 / 2020$

05/05/2020

$05 / 05 / 2020$

$06 / 05 / 2020$

$06 / 05 / 2020$

$06 / 05 / 2020$

$07 / 05 / 2020$

$07 / 05 / 2020$

$07 / 05 / 2020$

$08 / 05 / 2020$

$08 / 05 / 2020$

$09 / 05 / 2020$

$10 / 05 / 2020$

$11 / 05 / 2020$

$11 / 05 / 2020$

$11 / 05 / 2020$

$11 / 05 / 2020$

$11 / 05 / 2020$

$12 / 05 / 2020$

$12 / 05 / 2020$

$13 / 05 / 2020$

$13 / 05 / 2020$

$15 / 05 / 2020$

$15 / 05 / 2020$

$18 / 05 / 2020$

$18 / 05 / 2020$

$20 / 05 / 2020$

$20 / 05 / 2020$

26/05/2020

$30 / 05 / 2020$

$31 / 05 / 2020$ 
Tabela 1. Sequência cronológica dos países que decretaram oficialmente a utilização de máscaras faciais em locais públicos ${ }^{\star}$.

\begin{tabular}{lc}
\hline \multicolumn{1}{c}{ País } & Data da requisição \\
\hline Cazaquistão & Junho \\
Holanda & $01 / 06 / 2020$ \\
Maldivas & $01 / 06 / 2020$ \\
República Centro- & $12 / 06 / 2020$ \\
Africana & $12 / 06 / 2020$ \\
Bangladesh & \\
Reino Unido & $15 / 06 / 2020$ \\
Costa Rica & $15 / 06 / 2020$ \\
& $27 / 06 / 2020$ \\
Costa do Marfim & Julho \\
Brasil & $01 / 07 / 2020$ \\
Irã & $\mathbf{0 3 / 0 7 / 2 0 2 0}$ \\
\hline
\end{tabular}

${ }^{*} \mathrm{~A}$ depender do país, a requisição do uso de máscaras pode variar de 'qualquer' local público, para somente locais públicos específicos, como transportes públicos, shoppings, escolas, entre outros.

Fonte: Mask4All (https://masks4all.co/what-countries-requiremasks-in-public).

\section{Evidências acerca da efetividade do uso de máscaras como controle de doenças infecciosas respiratórias}

Estudos anteriores à atual pandemia já haviam comprovado a efetividade do uso massivo de máscaras, inclusive de máscaras de tecido, em locais extradomiciliares como estratégia de controle à disseminação de doenças infecciosas respiratórias ${ }^{10,18,44,56,125,126}$, incluindo a SARS ${ }^{127}$. De acordo com um estudo britânico ${ }^{128}$, a eficácia do uso de máscaras no combate a doenças respiratórias depende de três pontos principais: i) da capacidade de bloquear o vírus (eficácia da máscara); ii) da proporção de pessoas que a utilizam em público (aderência ao uso); e iii) da taxa de transmissão da doença.

Estudos ainda sugerem que, apesar de apresentarem uma eficácia menor do que as máscaras cirúrgicas, as máscaras de tecido, se usadas corretamente, funcionam como barreira mecânica à transmissão do vírus, impedindo ou reduzindo o contato dos indivíduos com gotículas contaminadas ${ }^{18,57,104,105,125,126,129,130}$. Esta redução ocorre porque, se uma gota contaminada atingir a trama do tecido de uma máscara ao invés da boca ou do nariz, ela tende a ficar retida, diminuindo o número de gotículas contaminadas que chegam às vias respiratórias. Ao evitar a contaminação de seus usuários, as máscaras de tecido ajudam a retardar a velocidade de evolução da epidemia ${ }^{38} \mathrm{e}$ contribuem para o estabelecimento de uma curva epidêmica mais longa e plana ${ }^{97}$. Contudo, se as máscaras forem posicionadas ao rosto de forma inadequada, com eventuais aberturas laterais, podem ter sua efetividade protetora diminuída em até $60 \%{ }^{54}$.

Pesquisadores da Universidade de Duke (EUA), analisaram 14 tipos de máscaras para avaliar sua eficácia na proteção contra gotículas respiratórias emitidas pela fala. Os resultados mostraram que, de fato, as máscaras profissionais N95 são as mais eficazes (redução da transmissão de gotículas para menos de $0,1 \%$ ), seguidas pelas máscaras cirúrgicas de três camadas ou de polipropileno e algodão (redução da transmissão de gotículas em $90 \%$ ou mais, em comparação com a ausência de cobertura facial). As máscaras de tecido de algodão, feitas à mão, vieram na sequência, fornecendo boa cobertura, eliminando $70 \%$ a $90 \%$ das gotículas expelidas pela fala, e se equiparando ao desempenho das máscaras N95 com válvulas ${ }^{131}$.

Ainda sobre o poder de filtração das máscaras de tecido, um estudo realizado em Teipei não encontrou diferenças significativas na concentração de partículas entre 20-1.000 nm no ar em ambientes fechados (carro e quarto) após a permanência de pessoas gripadas utilizando máscaras de tecido de três camadas versus estas mesmas pessoas utilizando máscaras cirúrgicas ${ }^{94}$, sugerindo poder de filtração semelhante entre os modelos. Nos Estados Unidos, diante da escassez de máscaras profissionais durante a pandemia da COVID-19, o CDC chegou a recomendar que fosse feito o uso de máscaras de tecido por profissionais de saúde que não atuam diretamente com pacientes infectados ${ }^{45}$.

\section{Evidências sobre o uso de máscaras em locais públicos na prevenção da COVID-19}

Com relação à proporção de pessoas que fazem o uso de máscaras, há grande heterogeneidade nas normas adotadas por diferentes países e regiões e, também, na taxa de aderência destas populações, mesmo mediante indicação ao uso de máscaras. A aderência das pessoas à medida de prevenção depende, entre outros fatores, da consistência da informação veiculada pelo poder público, da confiabilidade da população nas auto- 
ridades públicas e sanitárias e no conhecimento da população acerca da doença ${ }^{132}$. Entretanto, no final de março, cerca de três meses após o início da pandemia, Laestadius et al..$^{80}$ avaliaram as diretrizes e informações acerca do uso de máscaras em sites oficiais de agências e ministérios de saúde de 25 países e reportaram a falta de sistematização e alinhamento das informações prestadas à população.

O primeiro país a decretar a obrigatoriedade do uso de máscaras em locais públicos foi a Mongólia, em 14 de março, sucedido pelo Vietnã, Venezuela e República Tcheca ${ }^{133}$ (Tabela 1). Até o dia 13 de julho de 2020, seis meses após o início da pandemia, 129 países haviam passado a recomendar o amplo uso de máscaras em locais públicos, de forma geral ou mais restritiva. Em outros 17 países, a obrigatoriedade foi adotada em parte do território (municípios/estados) ${ }^{133}$. Ou seja, dos 193 países considerados Estados soberanos, até o dia 13 de Julho, 146 já se posicionavam favoravelmente ao uso de máscaras como medida preventiva à disseminação da COVID-19, destacando a relevância desta do ponto de vista de saúde pública (Figura 4). Para Li et al. ${ }^{89}$, a eficácia da obrigatoriedade do amplo uso de máscaras é uma das grandes lições desta pandemia. Atualmente, as máscaras são consideradas capazes de reduzir a gravidade da COVID-19, e possibilitar que as novas infecções sejam assintomáticas ${ }^{134}$.

Alguns países recomendaram o uso de máscaras no início da pandemia mesmo na ausência de evidências científicas consolidadas sobre a capacidade da medida de reduzir o seu ritmo de expansão da pandemia ${ }^{81}$, possivelmente pautados pelo princípio da precaução - definido como uma estratégia para abordar questões de dano potencial, quando falta um amplo conhecimento científico sobre o assunto. Segundo Greenhalgh et al. ${ }^{36}$, é necessário aplicar este princípio diante de questões de relevância para a proteção da saúde da população, principalmente quando análises de custo-benefício indicam poucos efeitos adversos potenciais e a possibilidade de alcançar benefícios significativos ${ }^{135}$.

Os efeitos benéficos da adoção precoce das máscaras de tecido por alguns países ficaram evidentes em estudos que comparam o avançar da COVID-19 em diferentes regiões e em estudos que realizaram rastreamento de casos de infecção por SARS-CoV2. Um estudo transnacional comparou, por exemplo, a evolução da pandemia na Áustria e República Tcheca, sugerindo a eficácia do uso de máscaras no combate à COVID-19 ${ }^{128}$. Ambos os países estabeleceram requisitos de dis- tanciamento social na mesma data, mas somente a República Tcheca incorporou, ao mesmo tempo, o uso obrigatório de máscaras. A partir daí, observou-se trajetória ascendente no número de infectados pelo coronavírus na Áustria, enquanto a curva epidêmica da República Tcheca manteve-se longa e plana. Apenas quando a Áustria também determinou por decreto governamental o uso de máscaras, os dois países voltaram a ter trajetórias similares ${ }^{128}$.

De forma similar, Cheng et al. ${ }^{40}$ compararam a evolução da incidência de COVID-19 em Hong Kong com a evolução da doença em outros oito países, e atribuíram a baixa taxa de contaminação em Hong Kong à adoção universal e voluntária do uso de máscaras pela maioria da população (96,6\% durante o estudo) no início da pandemia. Este mesmo estudo rastreou algumas rotas de transmissão entre os primeiros 961 casos reportados em Hong Kong, identificando que onze núcleos de infecção de 113 pacientes ocorreram em espaços de lazer sem uso de máscaras, incluindo restaurantes, karaokês e academias de ginástica, e que apenas três núcleos ocorreram em locais de trabalho onde o uso de máscaras era praticado ${ }^{53}$. Outros estudos epidemiológicos que rastrearam rotas de infecção e transmissão também concluíram que a taxa de transmissão foi menor em situações nas quais as máscaras foram utilizadas ${ }^{31,75}$.

A partir de dados sobre a evolução da pandemia na Itália e em Nova Iorque, ambos severamente atingidos pela COVID-19, Zhang et al. ${ }^{93}$ apontam que a obrigatoriedade de cobertura das vias respiratórias evitou mais de 76 mil e 66 mil novos casos de infecção pelo novo coronavírus, respectivamente ${ }^{93}$. As medidas que tornaram compulsório o uso de máscaras de tecido em ambientes públicos nos estados de Nova Iorque e Washington foram adotadas após modelos de predição indicarem que a adoção massiva de máscaras, mesmo as menos eficazes, poderia reduzir a transmissão do novo coronavírus colaborando para o achatamento da curva epidêmica $e$ dos picos de letalidade ${ }^{46,59}$. Outros estudos afirmam que a recomendação de manter a distância de dois metros quando em local público só é eficaz se a medida for associada ao uso de másca$\operatorname{ras}^{52,73}$. Alguns estudos sugerem que a pandemia de COVID-19 poderia ser contida se a maioria ou de preferência todas as pessoas usassem máscaras de tecido em locais públicos ${ }^{21,118,128,136}$.

Brooks et al. ${ }^{135}$ compararam o uso de máscaras à imunidade de rebanho obtida com vacinas, visto que quanto mais as pessoas aderem a essa medida preventiva em público (onde o distancia- 
mento social recomendado não é possível), maior é a proteção da comunidade ${ }^{135}$. Os mesmos autores afirmaram que a proteção em nível comunitário proporcionada pelo uso de máscaras de tecido pode reduzir o número de novas infecções e intervenções municipais mais perturbadoras da sociedade, como o fechamento do comércio e o lockdown - a política pública que exige que os cidadãos permaneçam em casa.

Ainda que diversos estudos indiquem a eficácia das máscaras no controle da pandemia e que um número crescente de países exija o uso das máscaras de tecido em ambientes extradomiciliares, a taxa de adesão pelas populações varia expressivamente. Certamente, a recomendação das autoridades sanitárias pelo uso de máscaras influencia o comportamento da população, conforme indica um estudo (ainda em preprint) realizado nos EUA que relata um aumento de $12 \%$ no uso de máscaras entre os americanos em apenas cinco dias após o anúncio do $\mathrm{CDC}^{137}$. Todavia, entre os estudos incluídos nessa narrativa, as maiores taxas de aderência ao uso de máscaras são de países asiáticos com histórico de uso desse recurso no controle de outras doenças infecciosas respiratórias e poluição do $\mathrm{ar}^{42,49,50,96,111}$.

As populações da Coreia do Sul e de Singapura, por exemplo, já vinham utilizando máscaras em público, especialmente depois do surto de SARS em 2003, o que facilitou a transposição da medida no cenário de pandemia pelo vírus SARS-CoV-2. Na Coreia do Sul, ainda no início da pandemia, mais de $60 \%$ da população já utilizava máscaras $^{50}$. Em Hong Kong, o uso de máscaras em ambientes extradomiciliares saltou de 74,5\% para 98,8\% entre os entrevistados, entre janeiro e março de $2020^{42}$. Diversos estudos em Hong Kong encontram taxas de aderência semelhante, entre $97 \%$ e $99 \% \%^{82}$, e o amplo uso de máscaras de tecido tem sido considerado uma das estratégias mais eficazes no combate à pandemia na região ${ }^{42}$. $\mathrm{Na}$ China, a adesão às máscaras é de mais de $80 \%{ }^{68,84,138}$. Em comparação, na Índia e na Malásia, estudos sobre comportamento do público com relação à pandemia indicou aderência mais baixa às máscaras, que são utilizadas por pouco mais de $70 \%$ e $51 \%$ dos entrevistados, respectivamente $^{96,111}$.

A efetividade do uso das máscaras de tecido para o controle da COVID-19 é bem suportada pela literatura quando em conjunto com outras medidas de combate à pandemia como a higienização correta das mãos e o distanciamento social $^{86}$. O uso das máscaras de tecido sem a adoção destas outras medidas não pode, entretanto, ser interpretado pelos usuários como solução para a crise sanitária, visto que sua eficácia, quando descumpridas outras recomendações, é ainda um tema controverso ${ }^{60,113}$.

\section{Evidências sobre o uso de máscaras na prevenção da COVID-19 no Brasil}

A avaliação dos padrões de buscas online no Brasil evidenciou um pico no interesse sobre o coronavírus no país no dia 21 de março, e um interesse expressivo da população brasileira acerca do uso de máscaras logo após a publicação da recomendação do MS ${ }^{115}$.

Os dois primeiros estados brasileiros a decretarem oficialmente a obrigatoriedade do uso de máscaras em ambientes extradomiciliares como medida adicional de combate à pandemia foram Pará e Santa Catarina, em 16 de abril, seguidos por Minas Gerais, Amapá e Goiás ${ }^{8}$ (Tabela 2). Já assoladas pela pandemia, as capitais Manaus e Rio de Janeiro fizeram o mesmo em 14/04 e $18 / 04$, respectivamente. A Figura 5 ilustra os estados brasileiros de acordo com o mês em que foi decretado oficialmente o uso obrigatório de máscaras em ambiente extradomiciliar.

Em nível federal, o Projeto de Lei (PL $1.562 / 2020$ ), que determinava o uso obrigatório de máscaras em locais públicos ou locais privados acessíveis ao público em todo o território nacional enquanto durasse o estado de calamidade pública decorrente da pandemia, foi aprovado pelo Plenário da Câmara dos Deputados em 9 de junho, e seguiu para sanção presidencial ${ }^{139}$. Porém, o presidente só sancionou a Lei no 14.019 no dia 2 de julho de $2020^{140}$, quando todos os estados brasileiros, exceto o Rio de Janeiro, já exigiam o uso de máscaras em ambientes extradomiciliares. Além disso, o presidente vetou importantes partes do PL, como o uso das máscaras em órgãos e entidades públicas e em estabelecimentos comerciais, industriais, templos religiosos, instituições de ensino e demais locais fechados em que haja aglomeração de pessoas. A Presidência também excluiu da proposta dispositivo que agravava a punição para infratores reincidentes ou que deixassem de usar máscara em ambientes fechados ${ }^{139}$. De acordo com o texto sancionado, os estabelecimentos também não serão obrigados a fornecer máscaras gratuitamente aos funcionários, e o poder público não será obrigado a fornecer o material a populações em situação de vulnerabilidade socioeconômica, conforme previsto pelo PL. É importante salientar que o fornecimento de máscaras a populações vulneráveis 
Tabela 2. Data em que os estados brasileiros sancionaram a obrigatoriedade do uso de máscaras em locais públicos.

\begin{tabular}{|c|c|}
\hline Estado $^{*}$ & Data \\
\hline & Abril \\
\hline $\mathrm{PA}^{1}$ & $16 / 04 / 2020$ \\
\hline $\mathrm{SC}^{2}$ & $16 / 04 / 2020$ \\
\hline $\mathrm{MG}^{3}$ & $17 / 04 / 2020$ \\
\hline $\mathrm{AP}^{4}$ & $18 / 04 / 2020$ \\
\hline $\mathrm{GO}^{5}$ & $19 / 04 / 2020$ \\
\hline $\mathrm{AC}^{6}$ & $20 / 04 / 2020$ \\
\hline $\mathrm{MA}^{7}$ & $20 / 04 / 2020$ \\
\hline $\mathrm{RS}^{8}$ & $20 / 04 / 2020$ \\
\hline $\mathrm{PI}^{9}$ & $22 / 04 / 2020$ \\
\hline $\mathrm{DF}^{10}$ & $23 / 04 / 2020$ \\
\hline $\mathrm{PE}^{11}$ & $23 / 04 / 2020$ \\
\hline $\mathrm{RO}^{12}$ & $26 / 04 / 2020$ \\
\hline $\mathrm{MT}^{13}$ & $27 / 04 / 2020$ \\
\hline $\mathrm{SE}^{14}$ & $27 / 04 / 2020$ \\
\hline $\mathrm{PR}^{15}$ & $28 / 04 / 2020$ \\
\hline \multirow[t]{2}{*}{$\mathrm{BA}^{16}$} & $29 / 04 / 2020$ \\
\hline & Maio \\
\hline $\mathrm{AL}^{17}$ & $04 / 05 / 2020$ \\
\hline $\mathrm{RN}^{18}$ & $04 / 05 / 2020$ \\
\hline $\mathrm{SP}^{19}$ & $04 / 05 / 2020$ \\
\hline $\mathrm{TO}^{20}$ & $05 / 05 / 2020$ \\
\hline $\mathrm{ES}^{21}$ & $08 / 05 / 2020$ \\
\hline $\mathrm{AM}^{22}$ & $13 / 05 / 2020$ \\
\hline $\mathrm{PB}^{23}$ & $16 / 05 / 2020$ \\
\hline $\mathrm{MS}^{24}$ & $18 / 06 / 2020$ \\
\hline $\mathrm{RR}^{25}$ & $27 / 05 / 2020$ \\
\hline \multirow[t]{2}{*}{$\mathrm{CE}^{26}$} & $30 / 05 / 2020$ \\
\hline & Junho \\
\hline $\mathrm{R}^{27}$ & $03 / 06 / 2020$ \\
\hline
\end{tabular}

${ }^{\star}$ LegisWeb, disponível em: https://www.legisweb.com.br/. Fontes: ${ }^{\text {DDecreto No }}$ 609, de 16/04/2020; ${ }^{2}$ Portaria SES No 251 de 16/04/2020; ${ }^{3}$ Decreto № 47.918, de 17/04/2020; ${ }^{4}$ Decreto No 1539 de 18/04/2020; ${ }^{5}$ Decreto No 9653 de 19/04/2020; ${ }^{6}$ Decreto No 5496 de 20/03/2020; ${ }^{7}$ Decreto No 35746 de 20/04/2020; ${ }^{8}$ Decreto No 17.099 de 20/04/2020; ${ }^{9}$ Decreto No 18947 de $22 / 04 / 2020$; ${ }^{10}$ Decreto No 40648 de $23 / 04 / 2020$; ${ }^{11}$ Decreto No 48969 de 23/04/2020; ${ }^{12}$ Decreto No 24979 de 26/04/2020; ${ }^{13}$ Decreto No 465 de $27 / 04 / 2020 ;{ }^{14}$ Decreto No 40588 de $27 / 04 / 2020$; ${ }^{15}$ Lei estadual № 20.189, de 28/04/2020; ${ }^{16}$ Lei estadual No 14261 de 29/04/2020; ${ }^{17}$ Decreto No 69722 de $04 / 05 / 2020$; ${ }^{18}$ Decreto No 29668 de $04 / 05 / 2020$; ${ }^{19}$ Decreto No 64959 de $04 / 05 / 2020$; ${ }^{20}$ Decreto No 6092 de $05 / 05 / 2020$; ${ }^{21}$ Decreto $N^{\circ} 4648$-R, de 08/05/2020; ${ }^{22}$ Decreto No 42278de $13 / 05 / 2020 ;{ }^{23}$ Decreto No 40242 de 16/05/2020; ${ }^{24}$ Decreto No 15456 de $18 / 06 / 2020$; ${ }^{25}$ Decreto No 28835 -E de 27/05/2020; ${ }^{26}$ Decreto No 33608 de $30 / 05 / 2020$; ${ }^{27}$ Lei estadual No 8.859 de 03/06/2020.

ou mesmo a toda a população de cidades ou regiões já é uma medida adotada pelos governos de outras nações ${ }^{66}$ e em alguns estados brasileiros, a exemplo da Bahia. Por esse e outros motivos, o governo brasileiro se tornou uma referência de como não proceder durante uma crise sanitária.

O uso das máscaras de tecido como uma medida adicional de proteção frente à pandemia de COVID-19 é especialmente relevante para populações em vulnerabilidade social diante da impossibilidade de adoção de medidas de distanciamento social em diversos contextos brasileiros, a exemplo das periferias e favelas e dos transportes públicos $^{34,39,40,42,46,59}$. De maneira geral, em situações de escassez de recurso, a entrega de máscaras deve ser estratégica e priorizar grupos de risco, além dos casos suspeitos ou confirmados de infecção, para a otimização do efeito de proteção a nível populacional ${ }^{33}$. Por outro lado, ressaltamos também a necessidade de considerar os potenciais efeitos da adoção desta medida protetiva para alguns segmentos da população, como quando aplicados recortes sociais para grupos etários e étnico-raciais. Especificamente, alertamos para a possibilidade de que o amplo uso de máscaras pela população negra exponha este grupo social a um maior assédio pela polícia e a situações de preconceito e injúria racial ${ }^{141}$; e que o amplo uso de máscaras prejudique a comunicação não verbal com grupos que já têm a sua capacidade de comunicação reduzida, a exemplo dos surdos e/ou mudos ${ }^{142}$.

\section{Discussão}

Esta síntese narrativa mostra a rápida evolução do conhecimento e a mudança de percepção a respeito desta medida de controle adicional à transmissão do SARS-CoV-2, revelando não apenas a contribuição científica prolífera e profusa em meio à pandemia, mas também como a COVID-19 tem desafiado os limites do conhecimento. O grande número de artigos publicados diariamente e a baixa qualidade de artigos envolvendo a temática, bem como a ausência de estudos observacionais sobre o uso correto das máscaras, revelam os principais desafios de se produzir revisões de forma mais oportuna em um momento onde a produção tem crescido exponencialmente.

Diante da evolução da pandemia e das evidências acumuladas nos últimos meses, a recomendação do amplo uso de máscaras de tecido em público se destaca como uma importante estratégia para: i) reduzir a propagação do novo coronavírus ${ }^{26,29,35,39,40,42,46,48,51,54-56,58,59,135}$; ii) reduzir a possibilidade do descarte inapropriado 


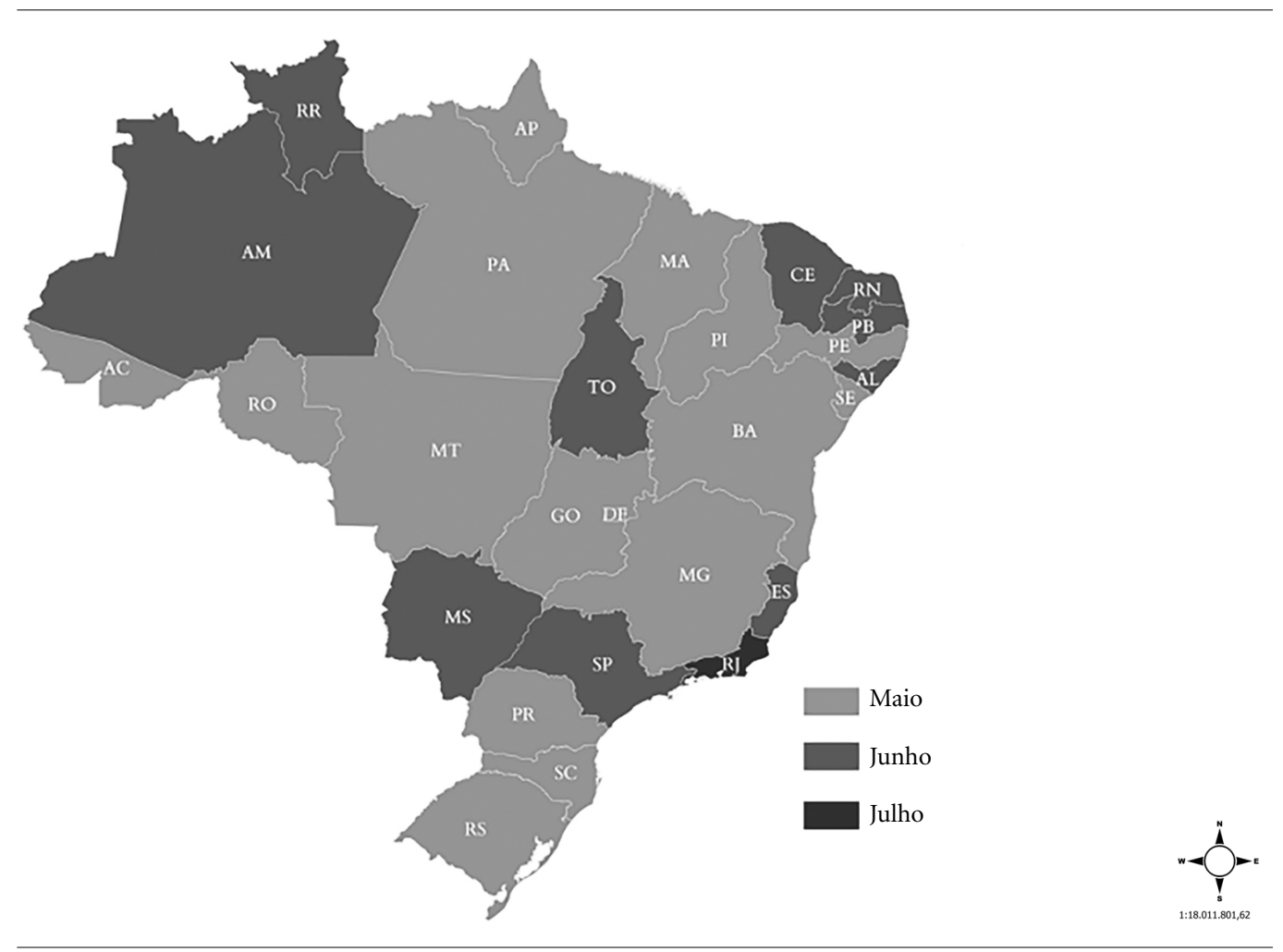

Figura 5. Estados brasileiros que sancionaram leis estabelecendo o uso mandatório de máscaras em ambientes extradomiciliares por mês de decreto oficialmente publicado.

Fonte: Site LegisWeb (https://www.legisweb.com.br/).

das máscaras descartáveis, que podem se tornar focos secundários de infecção da doença $\mathrm{a}^{20,72,122}$; e iii) ajudar na contenção da transmissão de outras doenças infectocontagiosas, como a influenza ${ }^{42,74,85,143}$, reduzindo a carga de doenças da população, a sobrecarga do sistema de saúde e permitindo melhor atendimento a quem dele necessita.

Dessa forma, a ampla adoção de máscaras de tecido pode ser vista também como um exemplo de dever cívico. Trata-se de um pequeno esforço e uma solução de baixa tecnologia altamente eficaz e capaz de mudar a trajetória epidemiológica dos países, favorecendo os esforços nacionais e globais contra a COVID-19135.

Essa revisão da literatura nos permitiu avaliar a nível nacional e internacional a relevância do uso de máscaras de tecido como medida adicional de proteção à transmissão do SARS-CoV-2. Apesar do seu escopo, essa revisão apresenta algumas limitações: i) a revisão narrativa pode ser criticada por não apresentar uma estrutura rígida como a revisão sistemática e a integrativa, entretanto, apresenta-se como uma alternativa adequada para identificar lacunas, explorar de forma crítica o tema ainda pouco conhecido ${ }^{144}$, além de ser realizada num tempo mais curto, a fim de contemplar a urgência de respostas visando o controle da pandemia; e ii) a inclusão de artigos em fase de pré-publicação (base MedRxiv) que ainda não passaram pela revisão por pares e podem ter sua qualidade questionada, porém isso se justifica pelo propósito de produzir evidências que deem suporte para recomendações para o controle da pandemia.

As evidências acumuladas nos poucos meses da epidemia fortalecem a ideia de que o amplo uso de máscaras de tecido em ambientes extradomiciliares é uma intervenção de saúde pública promissora que, associada às medidas preventivas de distanciamento social e de higienização das mãos, contribui para a redução da velocida- 
de de disseminação da COVID-19, reduzindo o número de casos e óbitos. Estas evidências foram rapidamente absorvidas para políticas públicas, na medida em que um número crescente de países vem adotando a obrigatoriedade do seu uso em locais públicos. Um estudo realizado na Alemanha mostrou que o uso de máscaras pela população foi percebido como um contrato social e a política de uso obrigatório das mesmas é mais justa que a política de uso voluntário ${ }^{145}$. Muitos entenderam que as evidências existentes fornecem elementos suficientes para ação baseada no princípio da precaução. Neste caso específico, trata-se de uma intervenção que tem o potencial de ter alta efetividade com baixo risco de efeitos $\operatorname{adversos}^{146}$.

No Brasil, onde vivenciamos a escassez de máscaras descartáveis, a reduzida capacidade de testagem e triagem de casos suspeitos e a existência de grandes adensamentos urbanos, muitos deles com moradias sem acesso a água e com elevada aglomeração intradomiciliar, o uso de máscaras de tecido pode ser ainda mais relevante no combate à propagação da doença. Seu uso se torna essencial sobretudo diante da flexibilização das medidas de distanciamento social e da implantação de estratégias para o retorno gradual às atividades ${ }^{40,47,147}$, que já começam a ser discutidas e realizadas por gestores públicos, apesar do contínuo agravamento da pandemia no país. As previsões atuais dos cenários pós-pandemia sugerem que o uso de máscaras de tecido em ambientes extradomiciliares será uma medida importante na desaceleração de uma possível segunda onda de contágio ${ }^{61,78}$. Ademais, cabem também ações educativas que promovam o uso correto de máscaras de tecido como uma nova norma social ${ }^{35,90}$.

Assim, são necessárias ações conjuntas entre as esferas do poder público no intuito de: i) apoiar ou desenvolver estratégias que possibilitem o aumento da produção e distribuição do produto à população, inclusive para doação aos grupos mais vulneráveis e com menos recursos, assim como sua comercialização em estabelecimentos comerciais que tenham permissão para seguirem abertos no período de pandemia; ii) incentivar e fomentar a produção caseira e a confecção de máscaras de tecido por costureiras autônomas, assegurando-lhes condições dignas de trabalho, remuneração e proteção à saúde; e iii) assegurar que grupos raciais ou socioeconomicamente desfavorecidos não sejam estigmatizados com a adoção de medidas compulsórias de uso de máscaras em ambientes extradomiciliares.

\section{Conclusão}

A ampla adesão ao uso de máscaras de tecido em ambientes extradomiciliares é uma intervenção eficaz que, em conjunto ao distanciamento social e higienização correta das mãos, tem sido adotada, em maior ou menor escala, por todos os continentes com o avançar da pandemia por contribuir com a redução da velocidade de transmissão do SARS-CoV-2.

Por fim, representam uma alternativa mais econômica, logisticamente viável e acessível para a população, além de ser ambientalmente sustentável e colaborar para a manutenção dos estoques das máscaras profissionais.

\section{Colaboradores}

N Ortelan, AJF Ferreira e L Leite planejaram, realizaram a busca, a triagem e a síntese dos artigos, elaboraram as figuras e tabelas e redigiram o manuscrito, contribuindo igualmente como primeiras autoras. JM Pescarini, AC Souto e ML Barreto auxiliaram na revisão do conteúdo. EML Aquino supervisionou a elaboração do documento e realizou a revisão crítica e correção final do manuscrito. Todos os autores aprovaram a versão final deste manuscrito.

\section{Agradecimentos}

Todos os autores são colaboradores da Rede CoVida e agradecem ao Grupo de Síntese de Evidências pelas discussões. Agradecemos Jessyca Teixeira pela ajuda na elaboração dos mapas. Luciana Leite agradece a bolsa de pós-doutorado financiada pela Coordenação de Aperfeiçoamento de Pessoal de Nível Superior - Brasil (CAPES) - Código de Financiamento 001. 


\section{Referências}

1. Centers for Disease Control and Prevention (CDC). Coronavirus Disease 2019 (COVID-19) - Prevention \& Treatment [Internet]. Washington: CDC; 2020 [acessado 2020 Maio 4]. Disponível em: https://www.cdc. gov/coronavirus/2019-ncov/prevent-getting-sick/ prevention.html

2. Ong SWX, Tan YK, Chia PY, Lee TH, Ng OT, Wong MSY, Marimuthu K. Air, Surface Environmental, and Personal Protective Equipment Contamination by Severe Acute Respiratory Syndrome Coronavirus 2 (SARS-CoV-2) From a Symptomatic Patient. JAMA 2020; 323(16):1610-1612.

3. van Doremalen N, Bushmaker T, Morris DH, Holbrook MG, Gamble A, Williamson BN, Tamin A, Harcourt JL, Thornburg NJ, Gerber SI, Lloyd-Smith JO, Wit E, Munster VJ. Aerosol and Surface Stability of SARS-CoV-2 as Compared with SARS-CoV-1. N Engl J Med 2020; 382(16):1564-1567.

4. Kampf G, Todt D, Pfaender S, Steinmann E. Persistence of coronaviruses on inanimate surfaces and their inactivation with biocidal agents. J Hosp Infect 2020; 104(3):246-251.

5. Ghinai I, McPherson TD, Hunter JC, Kirking HL, Christiansen D, Joshi K, Rubin R, Morales-Estrada S, Black SR, Pacilli M, Fricchione MJ, Chugh RK, Walblay KA, Ahmed NS, Stoecker WC, Hasan NF, Burdsall DP, Reese HE, Wallace M, Wang C, Moeller D, Korpics J, Novosad SA, Benowitz I, Jacobs MW, Dasari VS, Patel MT, Kauerauf J, Charles EM, Ezike NO, Chu V, Midgley CM, Rolfes MA, Gerber SI, Lu X, Lindstrom S, Verani JR, Layden JE, Illinois COVID-19 Investigation Team. First known person-to-person transmission of severe acute respiratory syndrome coronavirus 2 (SARS-CoV-2) in the USA. Lancet 2020; 395(10230):1137-1144.

6. World Health Organization (WHO). Shortage of personal protective equipment endangering health workers worldwide. Geneva: WHO; 2020.

7. Agência Nacional de Vigilância Sanitária (ANVISA). Orientações Gerais - Máscaras faciais de uso não profissional. Brasília: ANVISA; 2020.

8. Brasil. Ministério da Saúde (MS). Nota Técnica: Uso de máscaras caseiras. Brasília: MS; 2020.

9. World Health Organization (WHO). Responding to community spread of COVID-19: interim guidance [Internet]. Genebra: WHO; 2020 [acessado 2020 Maio 6]. Disponível em: https://apps.who.int/iris/ handle/10665/331421

10. Liang M, Gao L, Cheng C, Zhou Q, Uy JP, Heiner K, Sun C. Efficacy of face mask in preventing respiratory virus transmission: A systematic review and meta-analysis. Travel Med Infect Dis 2020; 36:101751.

11. Tong Z-D, Tang A, Li K-F, Li P, Wang H-L, Yi J-P, Zhang Y-L, Yan J-B. Potential Presymptomatic Transmission of SARS-CoV-2, Zhejiang Province, China, 2020. Emerg Infect Dis 2020; 26(5):1052-1054.

12. Bai Y, Yao L, Wei T, Tian F, Jin D-Y, Chen L, Wang M. Presumed Asymptomatic Carrier Transmission of COVID-19. JAMA 2020; 323(14):1406-1407.
13. Kimball A, Hatfield KM, Arons M, James A, Taylor J, Spicer K, Bardossy AC, Oakley LP, Tanwar S, Chisty Z, Bell JM, Methner M, Harney J, Jacobs JR, Carlson CM, McLaughlin HP, Stone N, Clark S, Brostrom-Smith C, Page LC, Kay M, Lewis J, Russell D, Hiatt B, Gant J, Duchin JS, Clark TA, Honein MA, Reddy SC, Jernigan JA, Public Health - Seattle \& King County, CDC COVID-19 Investigation Team. Asymptomatic and presymptomatic SARS-CoV-2 infections in residents of a long-term care skilled nursing facility-King County, Washington, March 2020. MMWR Morb Mortal Wkly Rep 2020; 69(13):377-381.

14. Wang Y, Wang Y, Chen Y, Qin Q. Unique epidemiological and clinical features of the emerging 2019 novel coronavirus pneumonia (COVID 19) implicate special control measures. J Med Virol 2020; 92(6):568576.

15. Huang R, Xia J, Chen Y, Shan C, Wu C. A family cluster of SARS-CoV-2 infection involving 11 patients in Nanjing, China. Lancet Infect Dis 2020; 20(5):534-535.

16. Kraemer MUG, Yang C-H, Gutierrez B, Wu C-H, Klein B, Pigott DM, Open COVID-19 Data Working Group, du Plessis L, Faria NR, Li R, Hanage WP, Brownstein JS, Layan M, Vespignani A, Tian H, Dye C, Pybus OG, Scarpino SV. The effect of human mobility and control measures on the COVID-19 epidemic in China. Science 2020; 368(6490):493-497.

17. Zou L, Ruan F, Huang M, Liang L, Huang H, Hong Z, Yu J, Kang M, Song Y, Xia J, Guo Q, Song T, He J, Yen H-L, Peiris M, Wu J. SARS-CoV-2 Viral Load in Upper Respiratory Specimens of Infected Patients. N Engl J Med 2020; 382(12):1177-1179.

18. Ma QX, Shan H, Zhang HL, Li GM. Potential utilities of mask-wearing and instant hand hygiene for fighting SARS-CoV-2. J Med Virol 2020; 92(9):1567-1571.

19. Ling Z, Xu X, Gan Q, Zhang L, Luo L, Tang X, Liu J. Asymptomatic SARS-CoV-2 infected patients with persistent negative CT findings. Eur J Radiol 2020; 126:108956.

20. Wang M-W, Zhou M-Y, Ji G-H, Ye L, Cheng Y-R, Feng $\mathrm{Z}-\mathrm{H}$, Chen J. Mask crisis during the COVID-19 outbreak. Eur Rev Med Pharmacol Sci 2020; 24(6):33973399.

21. Feng S, Shen C, Xia N, Song W, Fan M, Cowling BJ. Rational use of face masks in the COVID-19 pandemic. Lancet Respir Med 2020; 8(5):434-436.

22. World Health Organization (WHO). Advice on the use of masks in the community, during home care and in healthcare settings in the context of the novel coronavirus (COVID-19) outbreak [Internet]. 2020 [acessado 2020 Maio 6]. Disponível em: https://www.who.int/ publications/i/item/advice-on-the-use-of-masks-inthe-community-during-home-care-and-in-healthcare-settings-in-the-context-of-the-novel-coronavirus-(2019-ncov)-outbreak.

23. Chen Q, Allot A, Lu Z. Keep up with the latest coronavirus research. Nature 2020; 579(7798):193.

24. LegisWeb. LegisWeb [Internet]. [acessado 2020 Set 29]. Disponível em: https://www.legisweb.com.br/

25. Masks4All. What Countries Require or Recommend Masks In Public? [Internet]. [acessado 2020 Set 29]. Disponível em: https://masks4all.co/what-countriesrequire-masks-in-public 
26. Leung CC, Lam TH, Cheng KK. Let us not forget the mask in our attempts to stall the spread of COVID-19. Int J Tuberc Lung Dis 2020; 24(4):364-366.

27. Zhong B-L, Luo W, Li H-M, Zhang Q-Q, Liu X-G, Li W-T, Li Y. Knowledge, attitudes, and practices towards COVID-19 among Chinese residents during the rapid rise period of the COVID-19 outbreak: a quick online cross-sectional survey. Int J Biol Sci 2020; 16(10):1745-1752.

28. Adhikari SP, Meng S, Wu Y-J, Mao Y-P, Ye R-X, Wang Q-Z, Sun C, Sylvia S, Rozelle S, Raat H, Zhou H. Epidemiology, causes, clinical manifestation and diagnosis, prevention and control of coronavirus disease (COVID-19) during the early outbreak period: a scoping review. Infect Dis Poverty 2020; 9(1):29.

29. Leung CC, Lam TH, Cheng KK. Mass masking in the COVID-19 epidemic: people need guidance. Lancet 2020; 395(10228):945.

30. Zhai Z. Facial mask: A necessity to beat COVID-19. Build Environ 2020; 175:106827.

31. Liu X, Zhang S. COVID-19: Face masks and human-to-human transmission. Influenza Other Respi Viruses 2020; 14(4):472-473 .

32. Ma Q-X, Shan H, Zhang H-L, Li G-M, Yang R-M, Chen J-M. Potential utilities of mask-wearing and instant hand hygiene for fighting SARS-CoV-2. J Med Virol 2020; 92(9):1567-1571.

33. Worby CJ, Chang H-H. Face mask use in the general population and optimal resource allocation during the COVID-19 pandemic. Nat Commun 2020; 11(1):4049.

34. Zhou Z-G, Yue D-S, Mu C-L, Zhang L. Mask is the possible key for self-isolation in COVID-19 pandemic. J Med Virol 2020; 10.1002/jmv.25846.

35. Javid B, Weekes MP, Matheson NJ. Covid-19: should the public wear face masks? BMJ 2020; 369:m1442.

36. Greenhalgh T, Schmid MB, Czypionka T, Bassler D, Gruer L. Face masks for the public during the covid-19 crisis. BMJ 2020; 369:m1435.

37. Wang M-W, Cheng Y-R, Ye L, Zhou M-Y, Chen J, Feng Z-H. The COVID-19 outbreak: The issue of face masks. Infect Control Hosp Epidemiol 2020; 41(8):974975.

38. Han G, Zhou Y-H. Possibly critical role of wearing masks in general population in controlling COVID-19. J Med Virol 2020; 10.1002/jmv.25886

39. Gandhi M, Havlir D. The Time for Universal Masking of the Public for Coronavirus Disease 2019 Is Now. Open Forum Infect Dis 2020; 7(4):ofaa131.

40. Cheng KK, Lam TH, Leung CC. Wearing face masks in the community during the COVID-19 pandemic: altruism and solidarity. Lancet 2020; S01406736(20)30918-1

41. Pleil JD, Beauchamp JD, Risby TH, Dweik RA. The scientific rationale for the use of simple masks or improvised facial coverings to trap exhaled aerosols and possibly reduce the breathborne spread of COVID-19. J Breath Res 2020; 14(3):030201.

42. Cowling BJ, Ali ST, Ng TWY, Tsang TK, Li JCM, Fong MW, Liao Q, Kwan MY, Lee SL, Chiu SS, Wu JT, Wu $\mathrm{P}$, Leung GM. Impact assessment of non-pharmaceutical interventions against coronavirus disease 2019 and influenza in Hong Kong: an observational study. Lancet Public Health 2020; ;5(5):e279-e288 .
43. Desai AN, Aronoff DM. Masks and Coronavirus Disease 2019 (COVID-19). JAMA 2020; 323(20):2103.

44. MacIntyre CR, Hasanain SJ. Community Universal Face Mask Use during the COVID 19 pandemic-from households to travelers and public spaces. J Travel Med 2020; 27(3):taaa056.

45. Abd-Elsayed A, Karri J. Utility of Substandard Face Mask Options for Health Care Workers During the COVID-19 Pandemic. Anesth Analg; 131(1):4-6 .

46. Eikenberry SE, Mancuso M, Iboi E, Phan T, Eikenberry K, Kuang Y, Kostelich E, Gumel AB. To mask or not to mask: Modeling the potential for face mask use by the general public to curtail the COVID-19 pandemic. Infect Dis Model 2020; 5:293-308.

47. Thomson GA. COVID-19: Leaving lockdown-Of Schrodinger, cats, testing and masks. Int J Clin Pract 2020; 74(8):e13519.

48. Garcia LP. Use of facemasks to limit COVID-19 transmission. Epidemiol Serv Saude 2020; 29(2):e2020023.

49. Chen X, Ran L, Liu Q, Hu Q, Du X, Tan X. Hand Hygiene, Mask-Wearing Behaviors and Its Associated Factors during the COVID-19 Epidemic: A Cross-Sectional Study among Primary School Students in Wuhan, China. Int J Environ Res Public Health 2020; $17(8): 2893$.

50. Lee M, You M. Psychological and Behavioral Responses in South Korea During the Early Stages of Coronavirus Disease 2019 (COVID-19). Int J Environ Res Public Health 2020; 17(9):2977.

51. Cho-Han Chiang, Cho-Hung Chiang, Cho-Hsien Chiang, Yee-Chun Chen. The Practice of Wearing Surgical Masks during the COVID-19 Pandemic. Emerg Infect Dis 2020; 26(8):1962.

52. Setti L, Passarini F, De Gennaro G, Barbieri P, Perrone MG, Borelli M, Palmisani J, Di Gilio A, Piscitelli P, Miani A. Airborne Transmission Route of COVID-19: Why 2 Meters/ 6 Feet of Inter-Personal Distance Could Not Be Enough. Int J Environ Res Public Health 2020; 17(8):2932.

53. Cheng VCC, Wong S-C, Chuang VWM, So SY-C, Chen JH-K, Sridhar S, To KK-W, Chan JF-W, Hung IF-N, Ho P-L, Yuen K-Y. The role of community-wide wearing of face mask for control of coronavirus disease 2019 (COVID-19) epidemic due to SARS-CoV-2. $J$ Infect 2020; 81(1):107-114.

54. Konda A, Prakash A, Moss GA, Schmoldt M, Grant GD, Guha S. Aerosol Filtration Efficiency of Common Fabrics Used in Respiratory Cloth Masks. ACS Nano 2020; 14(5):6339-6347.

55. Victor CWT, Shing YT, Wai KP, Helen KWL, Shara WYL. A reality check on the use of face masks during the COVID-19 outbreak in Hong Kong. EClinicalMedicine 2020; 22:100356.

56. Wu E, Qi D. Masks and thermometers: Paramount measures to stop the rapid spread of SARS-CoV-2 in the United States. Genes Dis 2020; 10.1016/j.gendis.2020.04.011.

57. Wilson AM, Abney SE, King M-F, Weir MH, LópezGarcía M, Sexton JD, Dancer SJ, Proctor J, Noakes CJ, Reynolds KA. COVID-19 and non-traditional mask use: How do various materials compare in reducing the infection risk for mask wearers? J Hosp Infect 2020; 105(4):640-642. 
58. Sunjaya AP, Jenkins C. Rationale for universal face masks in public against COVID-19. Respirology 2020; 5(7):678-679.

59. Ngonghala CN, Iboi E, Eikenberry S, Scotch M, MacIntyre $\mathrm{CR}$, Bonds $\mathrm{MH}$, Gumel $\mathrm{AB}$. Mathematical assessment of the impact of non-pharmaceutical interventions on curtailing the 2019 novel Coronavirus. Math Biosci 2020; 325:108364.

60. MacIntyre CR, Chughtai AA. A rapid systematic review of the efficacy of face masks and respirators against coronaviruses and other respiratory transmissible viruses for the community, healthcare workers and sick patients. Int J Nurs Stud 2020; 108:103629.

61. Hoertel N, Blachier M, Blanco C, Olfson M, Massetti M, Rico MS, Limosin F, Leleu H. Lockdown exit strategies and risk of a second epidemic peak: a stochastic agent-based model of SARS-CoV-2 epidemic in France. medRxiv 2020; 10.1101/2020.04.30.20086264.

62. Szczesniak D, Ciulkowicz M, Maciaszek J, Misiak B, Luc D, Wieczorek T, Witecka K-F, Rymaszewska J. Psychopathological responses and face mask restrictions during the COVID-19 outbreak: Results from a nationwide survey. Brain Behav Immun 2020; 87:161162.

63. Kang Y-J. Lessons Learned From Cases of COVID-19 Infection in South Korea. Disaster Med Public Health Prep 2020; 1-8.

64. Clements JM. Knowledge and Behaviors Toward COVID-19 Among US Residents During the Early Days of the Pandemic: Cross-Sectional Online Questionnaire. JMIR Public Health Surveill 2020; 6(2):e19161.

65. Esposito S, Principi N. To mask or not to mask children to overcome COVID-19. Eur J Pediatr 2020; 179(8):1267-1270.

66. Parry J. Covid-19: Hong Kong government supplies reusable face masks to all residents. BMJ 2020; 369:m1880.

67. Soto DM, Cardona Maya WD, Agudelo EL, Bueno-Sánchez JC. The feasibility of generalized face mask usage during the COVID-19 pandemic: a perspective from Latin America. Infect Control Hosp Epidemiol 2020; 1-2.

68. Huang $\mathrm{Y}, \mathrm{Wu} \mathrm{Q}$, Wang $\mathrm{P}, \mathrm{Xu} \mathrm{Y}$, Wang $\mathrm{L}$, Zhao Y, Yao $\mathrm{D}, \mathrm{Xu} \mathrm{Y}, \mathrm{Lv} \mathrm{Q}, \mathrm{Xu}$ S. Measures Undertaken in China to Avoid COVID-19 Infection: Internet-Based, Cross-Sectional Survey Study. J Med Internet Res 2020; 22(5):e18718.

69. Sra HK, Sandhu A, Singh M. Use of Face Masks in COVID-19. Indian J Pediatr 2020; 87:553.

70. Kashyap A, Singh K, Sabat D, Maini L. Fast and economic cardboard cutout use to increase compliance of face mask wear during COVID-19 pandemic. J Clin Orthop Trauma 2020; 11(Supl. 3):S298-S300.

71. Matusiak Ł, Szepietowska M, Krajewski P, Białynicki-Birula R, Szepietowski JC. Inconveniences due to the use of face masks during the COVID-19 pandemic: A survey study of 876 young people. Dermatol Ther 2020; 33(4):e13567.

72. Ogoina D. COVID-19: The Need for Rational Use of Face Masks in Nigeria. Am J Trop Med Hyg 2020; 103(1):33-34.

73. Feng Y, Marchal T, Sperry T, Yi H. Influence of wind and relative humidity on the social distancing effectiveness to prevent COVID-19 airborne transmission: A numerical study. J Aerosol Sci 2020; 105585.
74. Noh JY, Seong H, Yoon JG, Song JY, Cheong HJ, Kim WJ. Social Distancing against COVID-19: Implication for the Control of Influenza. J Korean Med Sci 2020; 35(19):e182.

75. Gao Q, Hu Y, Dai Z, Xiao F, Wang J, Wu J. The epidemiological characteristics of 2019 novel coronavirus diseases (COVID-19) in Jingmen, Hubei, China. Medicine 2020; 99(23):e20605.

76. Clase CM, Fu EL, Joseph M, Beale RCL, Dolovich MB, Jardine M, Mann JFE, Pecoits-Filho R, Winkelmayer WC, Carrero JJ. Cloth Masks May Prevent Transmission of COVID-19: An Evidence-Based, Risk-Based Approach. Ann Intern Med 2020; 173(6):489-491

77. Chiang C-H, Chiang C-H, Chiang C-H. Letter to editor - Can universal masking help with our recovery from the COVID-19 pandemic? Int J Surg 2020; 79:125-126.

78. Goscé L, Phillips PA, Spinola P, Gupta DRK, Abubakar PI. Modelling SARS-COV2 Spread in London: Approaches to Lift the Lockdown. I Infect 2020; 81(2):260-265.

79. Middleton JD, Lopes H. Face masks in the covid-19 crisis: caveats, limits, and priorities. BMJ 2020; 369:m2030.

80. Laestadius L, Wang Y, Ben Taleb Z, Kalan ME, Cho Y, Manganello J. Online National Health Agency Mask Guidance for the Public in Light of COVID-19: Content Analysis. JMIR Public Health Surveill 2020; 6(2):e19501

81. Majeed A, Seo Y, Heo K, Lee D. Can the UK emulate the South Korean approach to covid-19? BMJ 2020; 369:m2084.

82. Chan EYY, Huang Z, Lo ESK, Hung KKC, Wong ELY, Wong SYS. Sociodemographic Predictors of Health Risk Perception, Attitude and Behavior Practices Associated with Health-Emergency Disaster Risk Management for Biological Hazards: The Case of COVID-19 Pandemic in Hong Kong, SAR China. Int J Environ Res Public Health 2020; 17(11):3869.

83. Han C, Shi J, Chen Y, Zhang Z. Increased flare of acne caused by long-time mask wearing during COVID-19 pandemic among general population. Dermatol Ther 2020; 33(4):e13704.

84. Liu X, Luo W-T, Li Y, Li C-N, Hong Z-S, Chen H-L, Xiao F, Xia J-Y. Psychological status and behavior changes of the public during the COVID-19 epidemic in China. Infect Dis Poverty 2020; 9(1):58.

85. Lee H, Lee H, Song K-H, Kim ES, Park JS, Jung J, Ahn S, Jeong EK, Park H, Kim HB. Impact of Public Health Interventions on Seasonal Influenza Activity During the SARS-CoV-2 Outbreak in Korea. Clin Infect Dis 2020; ciaa672.

86. Chu DK, Akl EA, Duda S, Solo K, Yaacoub S, Schünemann HJ, COVID-19 Systematic Urgent Review Group Effort (SURGE) study authors. Physical distancing, face masks, and eye protection to prevent person-to-person transmission of SARS-CoV-2 and COVID-19: a systematic review and meta-analysis. Lancet 2020; 395(10242):1973-1987

87. Liu PL. COVID-19 Information Seeking on Digital Media and Preventive Behaviors: The Mediation Role of Worry. Cyberpsychol Behav Soc Netw 2020; 23(10):677-682. 
88. Jung F, Krieger V, Hufert FT, Küpper J-H. How we should respond to the Coronavirus SARS-CoV-2 outbreak: A German perspective. Clin Hemorheol Microcirc 2020; 74(4):363-372.

89. Li DTS, Samaranayake LP, Leung YY, Neelakantan P. Facial protection in the era of COVID-19: A narrative review. Oral Dis 2020; 10.1111/odi.13460.

90. Goh Y, Tan BYQ, Bhartendu C, Ong JJY, Sharma VK. The face mask: How a real protection becomes a psychological symbol during Covid-19? Brain Behav Immun 2020; 88:1-5.

91. Greenhalgh T. Laying straw men to rest: author's reply to 'Urgency and uncertainty: covid-19, face masks, and evidence informed policy'. BMJ 2020; 369:m2240

92. Wong LP, Alias H, Danaee M, Ziaee M, Abedi F, Ziaee A, Mohajer S, HajiAliBeigloo R, Nia MN, Jamei F, Mazlom SR. Uncovering psychobehavioral implications of SARS-CoV-2 infection in Iran. Transbound Emerg Dis 2020; 10.1111/tbed.13662.

93. Zhang R, Li Y, Zhang AL, Wang Y, Molina MJ. Identifying airborne transmission as the dominant route for the spread of COVID-19. Proc Natl Acad Sci USA 2020; 117(26):14857-14863.

94. Ho K-F, Lin L-Y, Weng S-P, Chuang K-J. Medical mask versus cotton mask for preventing respiratory droplet transmission in micro environments. Sci Total Environ 2020; 735:139510.

95. Esposito S, Principi N, Leung CC, Migliori GB. Universal use of face masks for success against COVID-19: evidence and implications for prevention policies. Eur Respir J 2020; 55(6):2001260.

96. Dkhar SA, Quansar R, Saleem SM, Khan SMS. Knowledge, attitude, and practices related to COVID-19 pandemic among social media users in J\&K, India. Indian J Public Health 2020; 64(Supl.):S205-S210.

97. Mahase E. Covid-19: What is the evidence for cloth masks? BMJ 2020; 369:m1422.

98. Szarpak L, Smereka J, Filipiak KJ, Ladny JR, Jaguszewski M. Cloth masks versus medical masks for COVID-19 protection. Cardiol J 2020; 27(2):218-219.

99. Lazcano-Ponce E, Alpuche-Aranda C. Public health literacy in the face of the Covid-19 pandemic emergency. Salud Publica Mex 2020; 62(3):331-340.

100. Martin GP, Hanna E, Dingwall R. Urgency and uncertainty: covid-19, face masks, and evidence informed policy. BMJ 2020; 369:m2017.

101. Wu H-L, Huang J, Zhang CJP, He Z, Ming W-K. Facemask shortage and the novel coronavirus disease (COVID-19) outbreak: Reflections on public health measures. EClinicalMedicine 2020; 21:100329.

102. Stone TE, Kunaviktikul W, Omura M, Petrini M. Editorial: Facemasks and the Covid 19 pandemic: What advice should health professionals be giving the general public about the wearing of facemasks? Nurs Health Sci 2020; 22(2):339-342.

103. Chowdhury A, Jahan N, Wang S. One month of the novel coronavirus 2019 outbreak: Is it still a threat? Virusdisease 2020; 31(2):1-5.

104. Amendola L, Saurini MT, Di Girolamo F, Arduini F. A rapid screening method for testing the efficiency of masks in breaking down aerosols. Microchem J 2020; 157:104928.

105. Kim MN. What Type of Face Mask Is Appropriate for Everyone-Mask-Wearing Policy amidst COVID-19 Pandemic? J Korean Med Sci 2020; 35(20):e186.
106. Lam SKK, Hung MSY, Chien WT. Uncertainty surrounding the use of face masks in the community amid the COVID-19 pandemic. Int J Nurs Stud 2020; 108:103651.

107. King FM. Covid-19: face masks could foster distrust and blame. BMJ 2020; 369:m2009.

108. Cheng S-T. Covid-19: are face masks a good long term strategy? BMJ 2020; 369:m2005.

109. Lazzarino AI, Steptoe A, Hamer M, Michie S. Covid-19: Important potential side effects of wearing face masks that we should bear in mind. BMJ 2020; 369:m2003.

110. Schroter RC. Social distancing for covid-19: is 2 metres far enough? BMJ 2020; 369:m2010.

111. Azlan AA, Hamzah MR, Sern TJ, Ayub SH, Mohamad E. Public knowledge, attitudes and practices towards COVID-19: A cross-sectional study in Malaysia. PLoS One 2020; 15(5):e0233668.

112. Szepietowski JC, Matusiak Ł, Szepietowska M, Krajewski PK, Białynicki-Birula R. Face Mask-induced Itch: A Self-questionnaire Study of 2,315 Responders During the COVID-19 Pandemic. Acta Derm Venereol 2020; 100:adv00152.

113. Aggarwal N, Dwarakanathan V, Gautam N, Ray A Facemasks for prevention of viral respiratory infections in community settings: A systematic review and meta-analysis. Indian J Public Health 2020; 64(Supl.):S192-S200

114. Zhao M, Liao L, Xiao W, Yu X, Wang H, Wang Q, Lin YL, Kilinc-Balci FS, Price A, Chu L, Chu MC, Chu S, Cui Y. Household Materials Selection for Homemade Cloth Face Coverings and Their Filtration Efficiency Enhancement with Triboelectric Charging. Nano Lett 2020; 20(7):5544-5552.

115. Filho C, Vieira LJES, Silva RM. Buscas na internet sobre medidas de enfrentamento à COVID-19 no Brasil: descrição de pesquisas realizadas nos primeiros 100 dias de 2020. Epidemiol Serv Saúde 2020; 29(3):e2020191.

116. Han C, Shi J, Chen Y, Zhang Z. Increased flare of acne caused by long-time mask wearing during COVID 19 pandemic among general population. Dermatol Ther 2020; 33(4):e13704.

117. Luan R-S, Wang $X$, Sun $X$, Chen X-S, Zhou T, Liu Q-H, Lü X, Wu X-P, Gu D-Q, Tang M-S, Cui H-J, Shan X-F, Ouyang J, Zhang B, Zhang W, Emergency Research Group Sichuan University Covid. Epidemiology, Treatment, and Epidemic Prevention and Control of the Coronavirus Disease 2019: a Review. Sichuan Da Xue Xue Bao Yi Xue Ban 2020; 51(2):131-138.

118. Greenhalgh T, Schmid MB, Czypionka T, Bassler $\mathrm{D}$, Gruer L. Face masks for the public during the covid-19 crisis. BMJ 2020; 369:m1435.

119. Sugrue M, O'Keeffe D, Sugrue R, MacLean L, Varzgalis $\mathrm{M}$. A cloth mask for under-resourced healthcare settings in the COVID19 pandemic. Ir J Med Sci 2020; 189(4):1155-1157.

120. Lewis D. Is the coronavirus airborne? Experts can't agree. Nature 2020; 580(7802):175.

121. World Health Organization (WHO). Rational use of personal protective equipment for coronavirus disease (COVID-19): interim guidance, 27 February 2020. Genebra: WHO; 2020.

122. Bamber JH, Christmas T. Covid-19: Each discarded face mask is a potential biohazard. BMJ 2020; 369:m2012. 
123. Todd B. Where Are the Masks? Am J Nurs 2020; 120(6):18-19.

124. Lepelletier D, Grandbastien B, Romano-Bertrand S, Aho S, Chidiac C, Géhanno J-F, Chauvin F, French Society for Hospital Hygiene and the High Council for Public Health. What face mask for what use in the context of COVID-19 pandemic? The French guidelines. J Hosp Infect 2020; 105(3):414-418.

125. Brienen NCJ, Timen A, Wallinga J, van Steenbergen JE, Teunis PFM. The effect of mask use on the spread of influenza during a pandemic. Risk Anal 2010. 30(8):1210-1218.

126. Davies A, Thompson K-A, Giri K, Kafatos G, Walker J, Bennett A. Testing the efficacy of homemade masks: would they protect in an influenza pandemic? Disaster Med Public Health Prep 2013; 7(4):413-418.

127. Leung GM, Ho L-M, Chan SKK, Ho S-Y, Bacon-Shone J, Choy RYL, Hedley AJ, Lam T-H, Fielding R. Longitudinal assessment of community psychobehavioral responses during and after the 2003 outbreak of severe acute respiratory syndrome in Hong Kong. Clin Infect Dis 2005; 40(12):1713-1720.

128. Howard J, Huang A, Li Z, Tufekci Z, Zdimal V, van der Westhuizen H, von Delft A, Price A, Fridman L, Tang L, Tan V, Watson GL, Bax CE, Shaikh R, Questier F, Hernandez D, Chu LF, Ramirez CM, Rimoin AW. Face masks against COVID-19: an evidence review. Preprints 2020; 10.20944/preprints202004.0203.v1.

129. Milton DK, Fabian MP, Cowling BJ, Grantham ML, McDevitt JJ. Influenza virus aerosols in human exhaled breath: particle size, culturability, and effect of surgical masks. PLoS Pathog 2013; 9(3):e1003205.

130. Lustig SR, Biswakarma JJH, Rana D, Tilford SH, Hu W, Su M, Rosenblatt MS. Effectiveness of Common Fabrics to Block Aqueous Aerosols of Virus-like Nanoparticles. ACS Nano 2020; 14(6):7651-7658.

131. Fischer EP, Fischer MC, Grass D, Henrion I, Warren WS, Westman E. Low-cost measurement of face mask efficacy for filtering expelled droplets during speech. Sci Adv 2020; 6(36):eabd3083.

132. Goodman JL, Borio L. Finding Effective Treatments for COVID-19: Scientific Integrity and Public Confidence in a Time of Crisis. JAMA 2020; 323(19):18991900.

133. Masks4All. Quais países exigem máscaras em público ou recomendam máscaras? [Internet]. [acessado 2020 Jul 11]. Disponível em: https://masks4all.co/pt/whatcountries-require-masks-in-public/

134. Gandhi M, Rutherford GW. Facial Masking for Covid-19 - Potential for 'Variolation' as We Await a Vaccine. N Engl J Med 2020; 383(18):e101.

135. Brooks JT, Butler JC, Redfield RR. Universal Masking to Prevent SARS-CoV-2 Transmission-The Time Is Now. JAMA 2020; 10.1001/jama.2020.13107.

136. van der Sande M, Teunis P, Sabel R. Professional and home-made face masks reduce exposure to respiratory infections among the general population. PLoS One 2008; 3(7):e2618.

137. Goldberg MH, Gustafson A, Maibach EW, Ballew MT, Bergquist P, Kotcher JE, Marlon JR, Rosenthal SA, Leiserowitz A. Mask-wearing increases after a government recommendation: A natural experiment in the U.S. during the COVID-19 pandemic. Front Commun 2020; 5(44):1-6.
138. Chen Y, Jin YL, Zhu LJ, Fang ZM, Wu N, Du MX, Jiang MM, Wang J, Yao YS. The network investigation on knowledge, attitude and practice about COVID-19 of the residents in Anhui Province. Zhonghua Yu Fang Yi Xue Za Zhi 2020; 54(4):367-373.

139. Senado Federal. Bolsonaro veta uso obrigatório de máscara no comércio, em escolas e em igrejas [Internet]. Senado Notícias; 2020 [acessado 2020 Jul 11]. Disponível em: https://www12.senado.leg.br/noticias/ materias/2020/07/03/bolsonaro-veta-uso-obrigatorio-de-mascara-no-comercio-em-escolas-e-em-igrejas

140. Brasil. Lei $n^{\circ} 14.019$, de 2 de julho de 2020. Altera a Lei $n^{\circ} 13.979$, de 6 de fevereiro de 2020, para dispor sobre a obrigatoriedade do uso de máscaras de protecão individual para circulação em espaços públicos e privados acessíveis ao público, em vias públicas e em transportes públicos, sobre a adoção de medidas de assepsia de locais de acesso público, inclusive transportes públicos, e sobre a disponibilização de produtos saneantes aos usuários durante a vigência das medidas para enfrentamento da emergência de saúde pública de importância internacional decorrente da pandemia da Covid-19. Diário Oficial da União 2020; 8 set.

141. CNN. Why some people of color say they won't wear homemade masks [Internet]. 2020 [acessado 2020 Maio 4]. Disponível em: https://www.cnn. com/2020/04/07/us/face-masks-ethnicity-coronavirus-cdc-trnd/index.html

142. Martin V. Uso de máscaras prejudica comunicação dos surdos [Internet]. pleno.news 2020 [acessado 2020 Maio 4]. Disponível em: https://pleno.news/comportamento/pandemia-uso-de-mascaras-afeta-comunicacao-de-pessoas-surdas.html

143. Chow A, Hein AA, Kyaw WM. Unintended Consequence: Influenza plunges with public health response to COVID-19 in Singapore. J Infect 2020; 81(2):e68-e69.

144. Jesson J, Matheson L, Lacey FM. Doing Your Literature Review: Traditional and Systematic Techniques. Thousand Oaks: Sage Publications; 2011.

145. Betsch C, Korn L, Sprengholz P, Felgendreff L, Eitze S, Schmid P, Böhm R. Social and behavioral consequences of mask policies during the COVID-19 pandemic. Proc Natl Acad Sci USA 2020; 117(36):2185121853.

146. Greenhalgh T. Face coverings for the public: Laying straw men to rest. J Eval Clin Pract 2020; 26(4):10701077.

147. Instituto Brasileiro de Geografia e Estatística (IBGE). Sintese de indicadores sociais: uma análise das condições de vida da população brasileira: 2019 [Internet]. 2019 [acessado 2020 Maio 2]. Disponível em: https://biblioteca.ibge.gov.br/index.php/biblioteca-catalogo? view $=$ detalhes\&id $=2101678$

Artigo apresentado em 21/07/2020

Aprovado em 02/11/2020

Versão final apresentada em 04/11/2020

Editores chefes: Romeu Gomes, Antônio Augusto Moura da Silva 